\title{
A Collaboration-Resilience Framework For Disaster Management Supply Networks: A Case Study of the Philippines
}

\author{
Krichelle B.D. Medel, Rehana Kousar and Tariq Masood \\ University of Cambridge
}

\section{Author Accepted Manuscript (AAM) version}
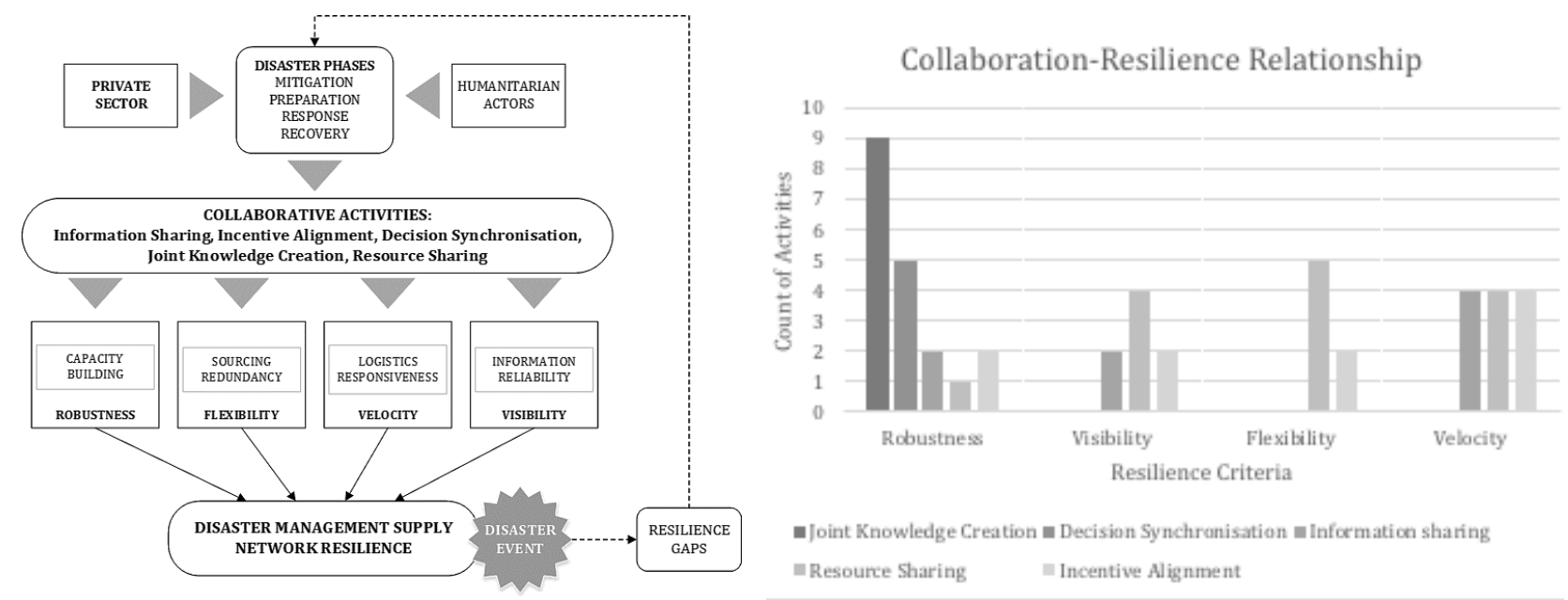

\section{Plain Language Summary}

The risk of disasters related to floods, tsunamis, earthquakes, and pandemics has increased over recent decades. This has inevitably demanded resilience strategies for effectively managing the disasters. By identifying 46 collaboration activities in Philippines, we show that planned collaboration, particularly with the private sector, can help to achieve resilience in the face of disasters.

License: This AAM version is deposited under the Creative Commons Attribution Non-commercial International Licence 4.0 (CC BY-NC 4.0). Any reuse is allowed in accordance with the terms outlined by the licence. To reuse the AAM for commercial purposes, permission should be sought by contacting permissions@emeraldinsight.com.

Citation details: Medel, K.B.D., Kousar, R. and Masood, T. (2020) 'A collaboration-resilience framework for disaster management supply networks: A case study of the Philippines', Journal of Humanitarian Logistics and Supply Chain Management, pp. 1-38, in press, first submitted 30/9/2019, accepted 24/5/2020, DOI: 10.1108/JHLSCM-09-20190066 . 


\title{
A Collaboration-Resilience Framework for Disaster Management Supply Networks: A Case Study of the Philippines
}

\author{
Krichelle B.D. Medel $^{1}$, Rehana Kousar, ${ }^{2,3}$, Tariq Masood ${ }^{1,2,4,5,{ }^{*}}$ \\ ${ }^{1}$ Institute for Manufacturing, Department of Engineering, University of Cambridge, 17 Charles \\ Babbage Road, Cambridge CB3 0FS, UK \\ ${ }^{2}$ Cambridge Global Challenges Strategic Research Initiative, University of Cambridge, JJ \\ Thompson Road, Cambridge CB3 0FS, UK \\ ${ }^{3}$ Biomakespace, Cambridge University Biomedical Innovation Hub, Clifford Allbutt Building, \\ Biomedical Campus, Hills Road, Cambridge, CB2 0AH, UK \\ ${ }^{4}$ Engineering Design Centre, Department of Engineering, University of Cambridge, Trumpington \\ Street, Cambridge CB2 1PZ, UK \\ ${ }^{5}$ Judge Business School, University of Cambridge, Trumpington Street, Cambridge CB2 1AG, UK

$$
\text { E*: tm487@cam.ac.uk }
$$

\section{Abstract}

Purpose: The increasing risk of natural disasters is challenging humanitarian actors to create resilient disaster management systems. However, the role of the private sector in disaster management operations (DMOs) is not as prominent as the role played by (inter)governmental agencies. This article aims to investigate the relationship of collaboration and resilience in disaster management supply networks (DMSNs).

Design/methodology/approach: Supply network resilience criteria were defined as robustness, flexibility, velocity and visibility based on the literature review. DMSN capabilities were identified characterising each resilience criterion through the development of the CollaborationResilience (COLRES) Analysis Framework for DMSNs. This theoretical model was then applied to an empirical case study in the Philippines using semi-structured interviews for data gathering.

Findings: A total of 46 cross-sector collaboration activities were identified across four disaster management phases and linked to the resilience criteria. A causal analysis of each collaboration activity and its outcome was conducted to identify relationships between collaboration types and resilience constructs. Based on these results, patterns were identified, and dependencies between collaboration and resilience were defined. Collective DMSN resilience (DMSNRES) enabled by existing cross-sector collaboration activities was evaluated against a future disaster scenario to identify resilience gaps. These gaps were used to recognise new cross-sector collaboration opportunities, thereby illustrating the continuous process of resilience building.

Originality/value: This research ultimately finds that cross-sector collaboration builds resilience in DMSNs through capacity building, redundancy sourcing, information reliability, and logistics responsiveness. This study shows that the private sector is able to go beyond existing short-term partnerships by participating in the 46 collaboration activities identified across four disaster management phases in order to build resilience in DMSNs.

\section{Plain Language Summary}

The risk of disasters related to floods, tsunamis, earthquakes, and pandemics has increased over recent decades. This has inevitably demanded resilience strategies for effectively managing the 
disasters. By identifying 46 collaboration activities in Philippines, we show that planned collaboration, particularly with the private sector, can help to achieve resilience in the face of disasters.

\section{Keywords}

Disaster management; Supply network; Resilience; Collaboration; Philippines; Flood; Tsunami; Earthquake; Pandemic; COVID-19

\section{Key abbreviations used}

BCP: Business Continuity Planning

COLRES: Collaboration-Resilience

CRED: Centre for Research on the Epidemiology of Disasters

CSN: Commercial Supply Network

DMO: Disaster Management Operation

DMSN: Disaster Management Supply Network

DMSNRES: DMSN Resilience

DROPS: Disaster Resilient Supply Chain Operations

DRR: Disaster Risk Reduction

DRRMC: Disaster Risk Reduction and Mitigation

Council

DS: Demand Synchronisation

EOC: Emergency Operations Centre

GDP: Gross Domestic Product

IA: Incentive Alignment

ICS: Incident Command System

IFRC: International Federation of Red Cross

IMF: International Monetary Fund

IS: Information Sharing

JICA: Japan International Cooperation Agency
JKC: Joint Knowledge Creation

LGU: Local Government Unit

MM: Metropolitan Manila

MMEIRS: Metropolitan Manila Earthquake Impact

Reduction Study

MSME: Micro, Small and Medium Enterprises

NDRP: National Disaster Response Plan

NDRRMC: National Disaster Risk Reduction and

Mitigation Council

NGO: Non-Governmental Organisation

PDRF: Philippine Disaster Resilience Foundation

PESTLE: Political, Economic, Social, Technological,

Legal and Environmental

PHIVOLCS: Philippine Institute of Volcanology and

Seismology

RQ: Research Question

RS: Resource Sharing

SCM: Supply Chain Management

SNAG: Supply Network Agility

SNRES: Supply Network Resilience

UN: United Nations

WFP: World Food Programme

WVF: West Valley Fault

\section{Introduction}

The occurrence of natural disasters has quadrupled in the last 10 years compared to 50 years ago (CRED, 2019). Humanitarian actors and government agencies are more motivated than ever to continuously improve DMOs to minimise casualties and costs from the growing frequency of disasters (Beltrán Guzmán et al., 2019; CRED, 2018). The Indian tsunami in 2004 highlighted the importance of supply chain management (SCM) in disaster management (Russell, 2005; ISM, 2005; Apta, 2009). Researchers suggest that effective commercial supply network (CSN) strategies may also be applicable in the humanitarian context in order to reach beneficiaries in a timely and costeffective way (Van Wassenhove, 2006; Oloruntoba and Gray, 2006; Kovács and Spens, 2007; Balcik et al., 2008, Besiou and Van Wassenhove, 2020), thus further propelling research in the humanitarian supply network and logistics domain. DMOs involve resource, financial and information flows throughout each phase, namely mitigation, preparation, response and recovery (Pujawan et al., 2009), which is a common characteristic of supply networks. The "ownership" of DMOs is mostly associated with the public sector (Matin, 2002), albeit it is recognized that no single organisation has enough capacity to solely respond to all the needs of an affected region (Bui et al., 2000). This favours a generally held view that organisations which complement each other are able to collaborate in disaster situations. Several studies have suggested that government collaboration with other sectors, private and humanitarian, may help improve the efficiency of DMOs (Tomasini and Van Wassenhove, 2009; Maon et al., 2009; Balcik et al., 2010; Banomyong and Julagasigorn, 2017; Prasanna and Haavisto, 2018) as well as collaborative performance using big data analytics (Dubey et al., 2019). While collaborations between the public sector and NGOs have already been institutionalised, there is still limited understanding as to how the private sector can be operationally involved in a disaster management supply network (DMSN). While the private and public sectors seemingly complement each other, further research indicates barriers to collaboration given each sector's motives, culture, capacities and expertise 
(Dahan et al., 2010). To date, the private sector's involvement in DMOs has been limited to short term and philanthropical financial contributions (Nurmala, 2018). It may, however, be possible to overcome such barriers through appropriate leadership approaches catering to organisational groups which are unlikely to be fused together (Salem et al., 2019; Ergun et al., 2014).

To effectively respond to unexpected events such as natural disasters, a supply network has to manifest resilience (Ponomarov and Holcomb, 2009) in order to provide the needed relief items. Masood et al. (2017) identified that the top five items needed in the case of a disaster include: communication devices, evacuation machinery, bottled water, food and medicine. While supply network resilience (SNRES) is predominantly researched in commercial contexts, the existence of studies on resilience in DMSNs is quite limited and is emerging as a topic of recent research in this domain (Masood et al., 2017; Altay and Pal, 2014; Altay and Green, 2006; Kovács and Spens, 2007; Overstreet et al., 2011; Singh et al., 2018). Collaboration has been commonly identified as a top contributor to commercial SNRES. However, there is a lack of information on whether the same relationship exists for collaboration and disaster management supply network resilience (DMSNRES). This article addresses a specific gap in the disaster management literature by investigating how cross-sectoral collaboration - in particular, between the humanitarian and the private sectors - can build resilience in DMSNs.

The remainder of this article is organised into seven sections. First, literature on DMSN, SNRES and collaboration is reviewed, and research gaps are identified upon which the research question is based (Section 2). Next, a discussion of the research methodology is presented to address the research question (Section 3), followed by the development of the theoretical model for the analysis of collaboration and resilience relationships in Section 4. This model is then applied to a case study of the Philippines in Section 5. Then, the results are analysed to validate the model and relate the findings back to the research objectives and literature (Section 6). Finally, the research concludes with its contributions to knowledge and implications for further research (Section 7).

\section{Literature Review}

The 2004 Indian tsunami served as a turning point for humanitarian actors in realising the criticality of effective supply network management to reach beneficiaries in a timely and cost-effective manner (Russell, 2005; ISM, 2005; Apta, 2009, Besiou and Van Wassenhove, 2020). At that time, 80\% of the logistics activities were focused on disaster relief operations (Van Wassenhove, 2006), implying a reactive approach to disaster management. Before the devastating tsunami in 2004, logistics and SCM in DMOs were not priorities for humanitarian actors (Özdamar et al., 2004), even though supply network management had been well established as a strategy to achieve cost-effectiveness in commercial operations (Croxton et al., 2001). Cooper et al. (1997) emphasise that supply network management goes beyond logistics and they highlight the importance of some level of integration within and between cross functional teams.

\subsection{DMSN}

In comparison to a commercial supply network (CSN), DMSNs operate in a completely different context, which poses additional complexities for DMSNs. The literature review methodology for DMSN is presented in Table 1. The results were also visualised using social network analysis (through VOSviewer v1.6.13). The density visualisations of co-occurrence analysis $(\mathrm{n}=968)$ and citation analysis $(\mathrm{n}=497$ with direct links only) are presented in Figure 1 and Figure 2 respectively.

Table 1. Literature review methodology for DMSN

\begin{tabular}{|c|c|c|c|}
\hline Domain & Keywords search on Scopus & $\begin{array}{l}\text { Title and Abstract } \\
\text { Screening }\end{array}$ & $\begin{array}{l}\text { Inclusion / Exclusion } \\
\text { Criteria }\end{array}$ \\
\hline $\begin{array}{l}\text { Disaster } \\
\text { Management } \\
\text { Supply Networks } \\
\text { (DMSN) }\end{array}$ & $\begin{array}{l}\text { TITLE-ABS-KEY ( "disaster" OR } \\
\text { "humanitarian" ) AND TITLE-ABS-KEY ( } \\
\text { "supply chain*" OR "supply network*" ) AND } \\
\text { PUBYEAR > } 2007 \text { AND PUBYEAR < 2020 } \\
\text { AND ( LIMIT-TO ( LANGUAGE,"English" ) ) } \\
\text { AND ( LIMIT-TO ( SUBJAREA,"BUSI" ) OR } \\
\text { LIMIT-TO ( SUBJAREA,"ENGI" ) OR LIMIT- } \\
\text { TO ( SUBJAREA,"DECI" ) ) } \\
968 \text { results }\end{array}$ & $\begin{array}{l}\text { Topic within the disaster } \\
\text { management context }\end{array}$ & $\begin{array}{l}\text { Inclusion criteria: } \\
\text { Focussed on strategic network } \\
\text { engineering aimed at building } \\
\text { resilience } \\
\text { Exclusion Criteria: } \\
\text { Optimisation studies aimed at } \\
\text { minimising costs } \\
\mathbf{2 3 1} \text { results }\end{array}$ \\
\hline
\end{tabular}




\section{analytic hierarchy process}

supply chain management in dis

performance measurement

$$
\text { crisis management }
$$

humanitarian supply chain

vehicle routing

humanitarian logistics decision support tools

$$
\text { societies and institutions facility location }
$$

agility disaster response disaster relief facility locations

supply chain management

$$
\begin{aligned}
& \text { service supply chains private sectors sustainable development inventory integer programming } \\
& \text { system theory } \\
& \text { resilience computational results } \\
& \text { climate change losses manufacture uncertainty stochastic models } \\
& \text { risk assessment supply networks demandanalysis } \\
& \begin{array}{lll}
\text { human } & \text { chains } & \text { reliability }
\end{array} \\
& \text { catastrophic event economics demand uncertainty } \\
& \text { life cycle natural and man-made disasters } \\
& \text { reliability analysis } \\
& \text { crime water supply networks }
\end{aligned}
$$

Figure 1: DMSN Density Visualisation - Co-Occurrence Analysis (n=968)

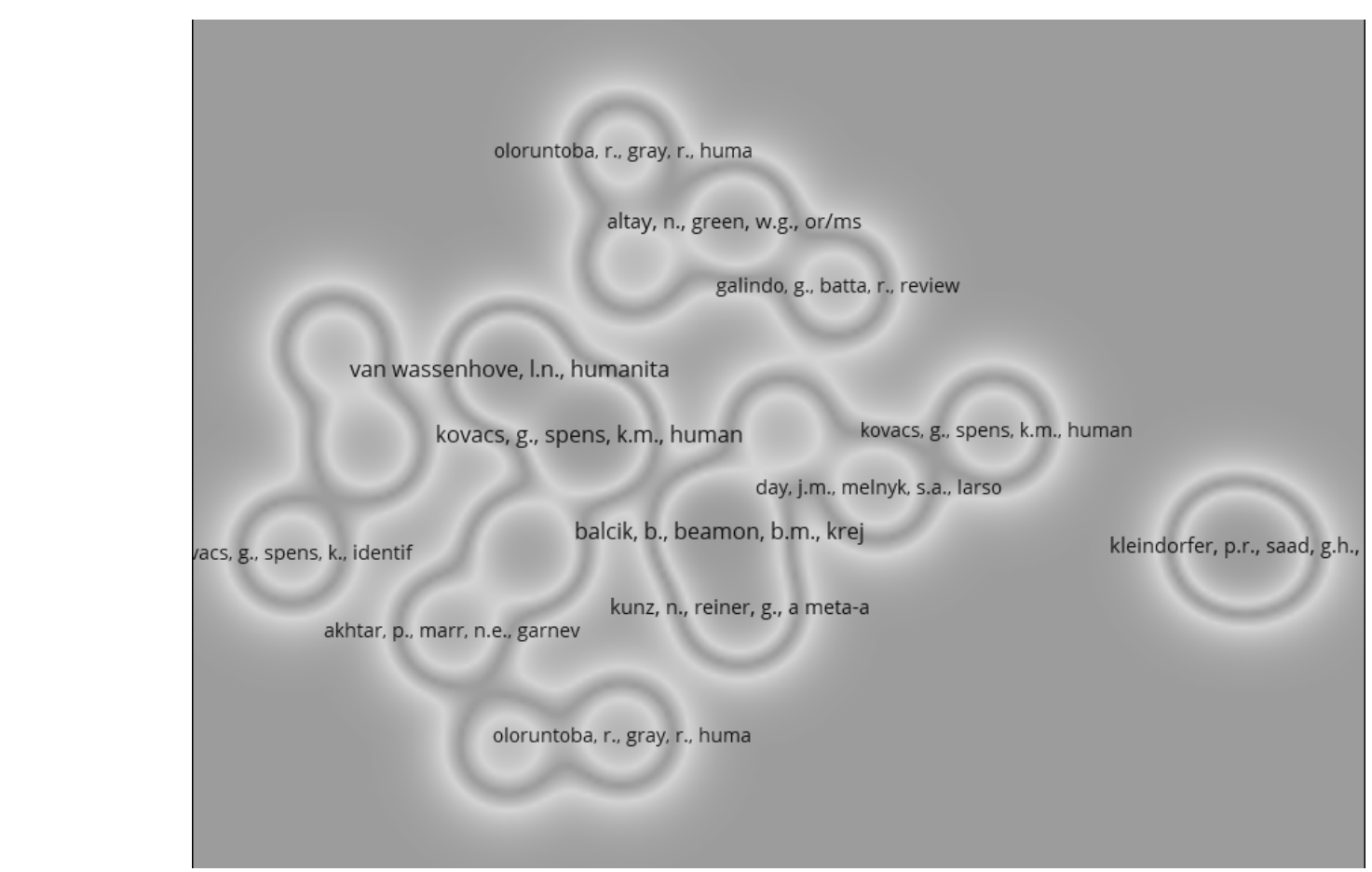

Figure 2: DMSN Density Visualisation - Citation Analysis ( $n=968$, in display $n=497$ with direct links only)

Characteristics of DMSNs were identified through the keyword search of disaster supply networks according to the theme of network engineering studies. Table 2 presents complexities in humanitarian supply chains identified through the literature review. Unpredictability tops the list characterising a DMSN and pertains to the disaster type, intensity, time, location and demand requirements (Hellingrath et al., 2013; Olaogbebikan and Oloruntoba, 2017). This is closely related to very short lead times imposed on DMSN actors and the need to always act with urgency. Furthermore, DMSNs are characterised by higher stakes such that the welfare of the communities is at stake. 
Turbulent environments characterised by the lack of constant sources of critical needs and sporadic information flow continue to burden the establishment of stable processes in the context of a DMO.

Table 2. Complexities in Humanitarian Supply Chains

\begin{tabular}{|c|c|c|c|c|c|c|c|c|c|c|c|c|c|}
\hline & \multicolumn{12}{|c|}{ Complexities } \\
\hline & & 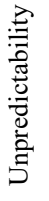 & 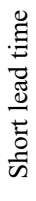 & 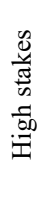 & 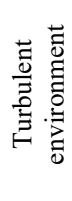 & 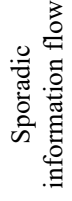 & 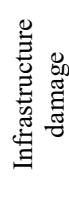 & 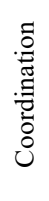 & 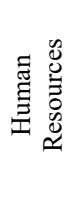 & 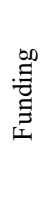 & 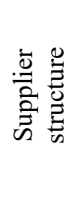 & 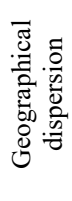 & 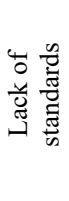 \\
\hline \multirow{11}{*}{$\frac{\vdots}{\vdots}$} & Oloruntoba and Gray, 2006 & $\mathrm{x}$ & & & $\mathrm{x}$ & $\mathrm{x}$ & & & & & & $\mathrm{x}$ & \\
\hline & Van Wassenhove, 2006 & $\mathrm{x}$ & & & & & & & & & & & \\
\hline & Kovács and Spens, 2007 & & $\mathrm{x}$ & $\mathrm{x}$ & & & $\mathrm{x}$ & & & & $\mathrm{x}$ & & \\
\hline & Maon et al., 2009 & $\mathrm{x}$ & $\mathrm{x}$ & $\mathrm{x}$ & & $\mathrm{x}$ & $\mathrm{x}$ & $\mathrm{x}$ & & & & $\mathrm{x}$ & \\
\hline & Kovács and Spens, 2009 & & & & & & $\mathrm{x}$ & $\mathrm{x}$ & $\mathrm{x}$ & & & & $\mathrm{x}$ \\
\hline & Tomasini and Van Wassenhove, 2009a & $\mathrm{x}$ & $\mathrm{x}$ & $\mathrm{x}$ & $\mathrm{x}$ & $\mathrm{x}$ & $\mathrm{x}$ & $\mathrm{x}$ & $\mathrm{x}$ & $\mathrm{x}$ & & & \\
\hline & Tomasini and Van Wassenhove, 2009b & $\mathrm{x}$ & $\mathrm{x}$ & $\mathrm{x}$ & $\mathrm{x}$ & $\mathrm{x}$ & & $\mathrm{x}$ & $\mathrm{x}$ & $\mathrm{x}$ & $\mathrm{x}$ & & \\
\hline & Overstreet et al., 2011 & $\mathrm{x}$ & $\mathrm{x}$ & & & & $\mathrm{x}$ & & $\mathrm{X}$ & $\mathrm{x}$ & & & \\
\hline & Hellingrath et al., 2013 & $\mathrm{x}$ & $\mathrm{x}$ & & $\mathrm{x}$ & $\mathrm{x}$ & & & & & $\mathrm{x}$ & & \\
\hline & Olaogbebikan and Oloruntoba, 2017 & $\mathrm{x}$ & $\mathrm{x}$ & $\mathrm{x}$ & & $\mathrm{x}$ & & $\mathrm{x}$ & & $\mathrm{x}$ & & & \\
\hline & Gatti, 2017 & & $\mathrm{x}$ & $\mathrm{x}$ & $\mathrm{x}$ & & & & $\mathrm{x}$ & $\mathrm{x}$ & & & \\
\hline
\end{tabular}

\subsection{SNRES}

SNRES has been defined as the "capability of the supply network to prepare for unexpected events, respond to disruptions, and recover from them" (Ponomarov and Holcomb, 2009). SNRES, along with supply network agility (SNAG), has been found to significantly impact pre-disaster operations. However, SNRES only continues to have a substantial effect up to post-disaster operations (Altay et al., 2018). As such, it is more important for DMSNs to be resilient since they are the backbone of relief and recovery activities.

The literature review methodology for SNRES is presented in Table 3. The results were also visualised using social network analysis (through VOSviewer v1.6.13). The density visualisations of co-occurrence analysis $(\mathrm{n}=476)$ and citation analysis ( $\mathrm{n}=358$ with direct links only) are presented in Figure 3 and Figure 4 respectively.

\section{Table 3. Literature review methodology for SNRES}

\begin{tabular}{|l|l|l|l|}
\hline Domain & Keywords search on Scopus & $\begin{array}{l}\text { Title and Abstract } \\
\text { Screening }\end{array}$ & $\begin{array}{l}\text { Inclusion / Exclusion } \\
\text { Criteria }\end{array}$ \\
\hline $\begin{array}{l}\text { Supply Network } \\
\text { Resilience } \\
\text { (SNRES) }\end{array}$ & $\begin{array}{l}\text { TITLE-ABS-KEY ( "supply chain } \\
\text { resilience" OR "supply network } \\
\text { resilience" ) OR TITLE-ABS-KEY ( "resilient } \\
\text { supply chain" OR "resilient supply } \\
\text { network" ) AND PUBYEAR > 2007 AND P } \\
\text { UBYEAR < 2020 AND (LIMIT- } \\
\text { TO ( LANGUAGE, "English") ) } \\
\end{array}$ & $\begin{array}{l}\text { Topic focuses on building } \\
\text { resilience within a supply chain }\end{array}$ & $\begin{array}{l}\text { Inclusion Criteria: } \\
\text { Provides insights on enablers of } \\
\text { resilience or how resilience is } \\
\text { built in supply networks }\end{array}$ \\
\\
476 results & 84 results & \\
\end{tabular}




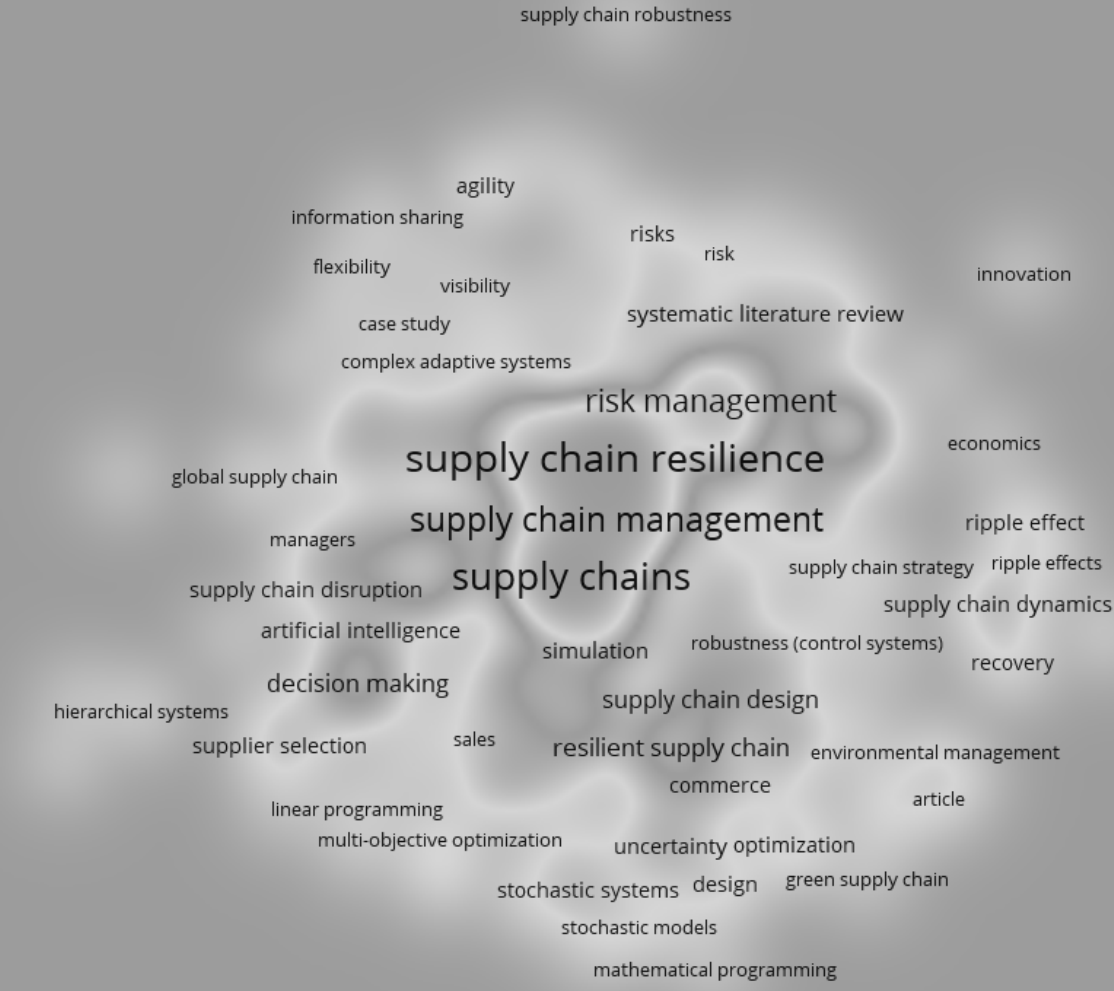

Figure 3: SNRES - Co-Occurrence Analysis ( $n=476)$

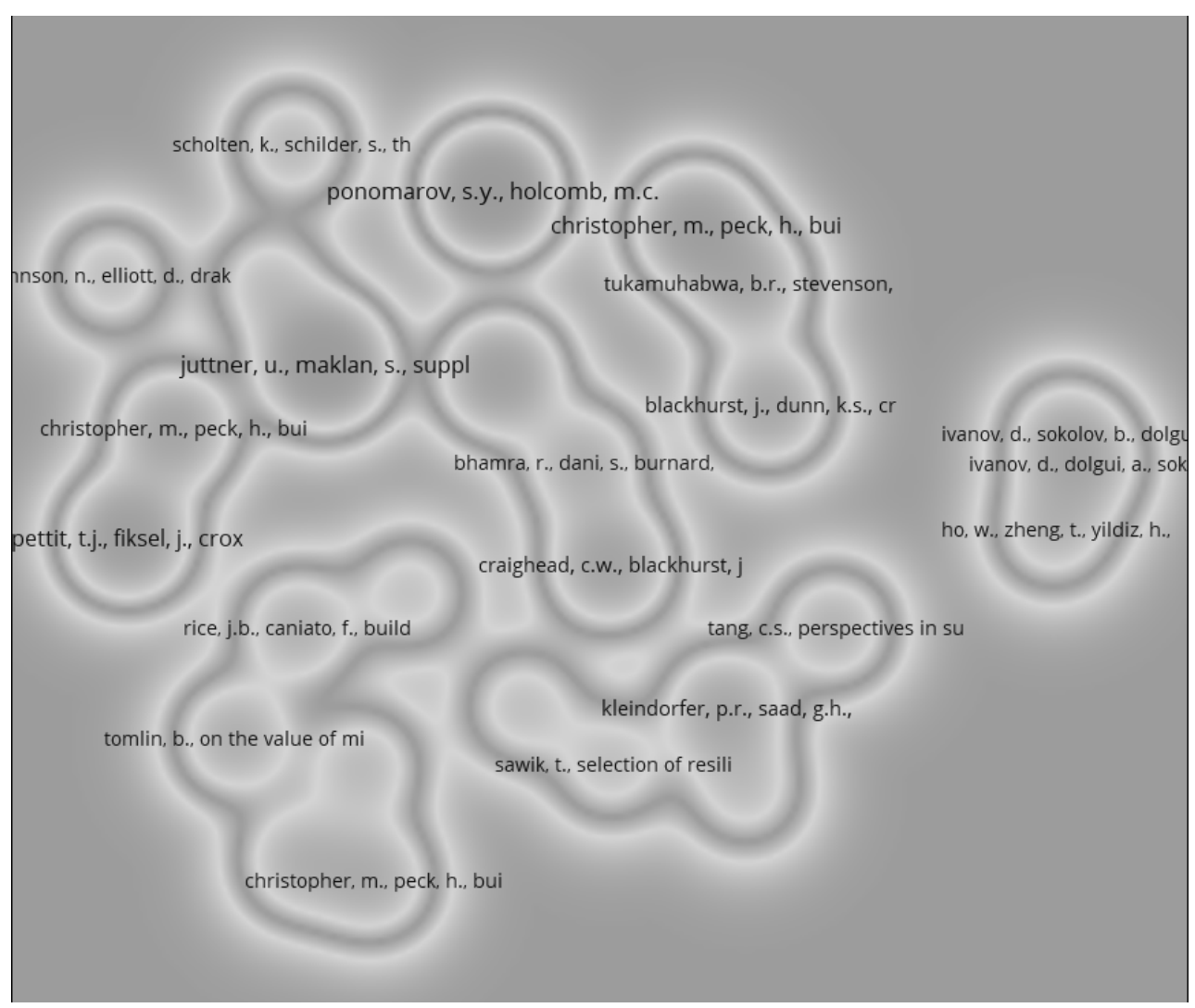

Figure 4: SNRES - Citation Analysis ( $n=476$, in display $n=358$ with direct links only) 
Nineteen resilience constructs and their definitions were identified through keyword searches of SNRES literature (see Table 4). Authors of existing literature use some constructs interchangeably. In particular, agility and velocity both pertain to timeliness within the supply chain. In line with the constructs put forward by Jüttner and Maklan (2011), velocity is used in this study. Authors also have a varied understanding of the constructs, such that a firstorder construct for one author may be a second-order construct for others. For example, redundancy is viewed as either a construct to achieve flexibility (Sheffi and Jr, 2005; Jüttner and Maklan, 2011; Dubey et al., 2014) or a pillar separate from flexibility (Tukamuhabwa et al., 2015; Hohenstein et al., 2015; Chowdhury and Quaddus, 2016; Ivanov and Dolgui, 2018). In contrast, Välikangas (2010) shows that most enablers identified in the literature fall within only two main constructs, namely robustness and agility. This finding has formed the basis for many other studies that have focused on either robustness (Durach et al., 2015) or agility (Dubey et al., 2014; Gligor et al., 2019; Rasouli, 2019) as the main enablers of resilience. These identified resilience constructs have been found to be applicable to disaster management contexts as well (Scholten et al., 2014). Day (2014) proposes that resilience encompasses all disaster management phases in which the flow of resources, information and finances should be coordinated.

\section{Table 4. Resilience constructs and their definitions}

\begin{tabular}{|c|c|}
\hline Resilience constructs & Definitions \\
\hline Collaboration & Working together to create something new (Ergun et al., 2004; Juttner and Maklan, 2011) \\
\hline Velocity & The pace of response to a disruption (Jüttner and Maklan, 2011) \\
\hline Visibility & $\begin{array}{l}\text { The ability to see all relevant information such as the location of supply network members or the status of products } \\
\text { and services (Johnson et al., 2013) }\end{array}$ \\
\hline Flexibility & $\begin{array}{l}\text { Flexibility refers to having viable alternatives such as back-up suppliers, manufacturing facilities, and a multi- } \\
\text { skilled workforce (Sheffi and Jr, 2005). See Baharmand et al. (2017) for a flexibility assessment of DMSN in } 2015 \\
\text { Nepal earthquake. }\end{array}$ \\
\hline Robustness & $\begin{array}{l}\text { The ability to resist change without changing the initial configuration (Wieland and Wallenburg, 2013; Masood et } \\
\text { al., 2017b; Masood et al., 2016) }\end{array}$ \\
\hline Anticipation & To forecast possible future changes (Wieland and Wallenburg, 2013) \\
\hline Adaptability & $\begin{array}{l}\text { The capacity of the supply chain to self-organise and reconfigure its structure and behaviour to satisfy new } \\
\text { conditions (Lee, 2004; Masood et al., 2017b; Masood et al., 2016) }\end{array}$ \\
\hline Risk Management & $\begin{array}{l}\text { The identification of potential sources of risks and the implementation of strategies to reduce vulnerability } \\
\text { (Masood et al. 2017a; Juttner et al, 2003) }\end{array}$ \\
\hline Recovery & The ability to bounce back from the post-disruption state (Ponomarov and Holcomb, 2009) \\
\hline Knowledge Management & $\begin{array}{l}\text { The sharing of common understandings, awareness of risks and learning from past disruptions (Faisal et al., 2006; } \\
\text { Ponomarov and Holcomb, 2009) }\end{array}$ \\
\hline Preparedness & Resistance to forecasted changes (Wieland and Wallenburg, 2013) \\
\hline HR Management & $\begin{array}{l}\text { The training and education of employees in dealing with risk events and the establishment of sub teams } \\
\text { (Blackhurst et al., 2011) }\end{array}$ \\
\hline Sustainability & $\begin{array}{l}\text { Using resources to meet the needs of the present without compromising the ability of future generations to meet } \\
\text { their own needs (Daly and Cobb 1994). }\end{array}$ \\
\hline Transparency & End-to-end integration of orders, inventory, transportation and distribution (Smith, 2004) \\
\hline Culture & Mindset setting to engender risk management with everyone in the organisation (Christopher and Peck, 2004) \\
\hline Innovativeness & Openness and the capacity to introduce innovation into the organization (Hult et al., 2004) \\
\hline Trust & To rely on an exchange partner in whom one has confidence (Moorman, Deshpande, and Zaltman 1993). \\
\hline Data Analytics & $\begin{array}{l}\text { The use of (big) data analytics for disaster resilient supply chain operations (DROPS) (Masood et al., 2017); the } \\
\text { use of analytics to reduce uncertainty (Dubey et al., 2019) }\end{array}$ \\
\hline Futureproofing & $\begin{array}{l}\text { The process of making provision for future developments, needs or events that impact the current processes. } \\
\text { (Masood et al., 2017b; Masood et al., 2016) }\end{array}$ \\
\hline
\end{tabular}

Each resilience construct was checked across literature identified in Table 4. Collaboration ranked the highest out of all constructs, followed by velocity, visibility, and flexibility (see Table 5). Although collaboration ranked the highest resilience enabler, studies highlighting its influence on SNRES are minimal. In comparison to Jüttner and Maklan (2011), Scholten and Schilder (2015) hold the view that collaboration is an antecedent of visibility, velocity and flexibility, and thus, a second-order enabler to resilience, thereby emphasising its heightened importance as it is needed to improve on the other three constructs. Jüttner and Maklan (2011) explain that the mutual dependence of organisations indirectly impacts SNRES as it results in a high level of collaboration. The same authors also report that organisations with low levels of collaborative activities can be resilient as long as there is enough mutually created knowledge over the years. This can be explained by organisations which have very few transactional touchpoints but have created processes together and have accumulated jointly created knowledge over time. 
Table 5. Constructs of Supply Chain Resilience

\begin{tabular}{|c|c|c|c|c|c|c|c|c|c|c|c|c|c|c|c|c|c|c|c|}
\hline $\begin{array}{r}\text { Resilience Constructs } \rightarrow \\
\text { Authors } \downarrow \\
\end{array}$ & 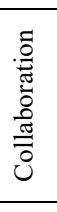 & $\begin{array}{l}\frac{3}{0} \\
\frac{0}{0} \\
>\end{array}$ & 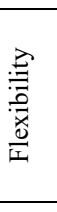 & 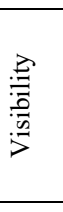 & 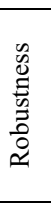 & 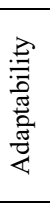 & 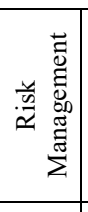 & 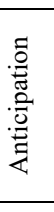 & 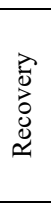 & 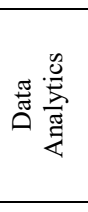 & 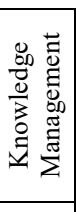 & 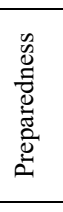 & 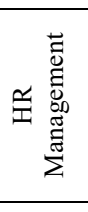 & 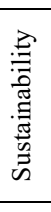 & 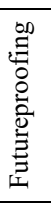 & 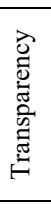 & $\begin{array}{l}\stackrel{\Xi}{\Xi} \\
\text { J }\end{array}$ & 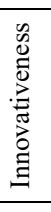 & $\underset{E}{\overrightarrow{2}}$ \\
\hline Sá et al., 2019 & $\mathrm{x}$ & & $\mathrm{x}$ & $\mathrm{x}$ & & $\mathrm{x}$ & & $\mathrm{x}$ & & & & & & & & & & & \\
\hline Rasouli, 2019 & & $\mathrm{x}$ & & & & & & & & & & & & & & & & & \\
\hline Dubey et al., 2019 & & & & & & & & & & $\mathrm{x}$ & & & & & & & & & \\
\hline Ivanov and Dolgui, 2018 & & & $\mathrm{x}$ & & $\mathrm{x}$ & & & & & & & & & & & & & & \\
\hline Namdar et al., 2018 & $\mathrm{x}$ & & & $\mathrm{x}$ & & & & & & & & & & & & & & & \\
\hline Treiblmaier, 2018 & & $\mathrm{x}$ & & & & & & & $\mathrm{x}$ & & & & & & & & & & \\
\hline Masood et al., 2017a & & & & & & & $\mathrm{x}$ & & & & & & & & & & & & \\
\hline Masood et al., 2017b & & & $\mathrm{x}$ & & $\mathrm{x}$ & $\mathrm{x}$ & $\mathrm{x}$ & & & $\mathrm{x}$ & & & & & & & & & \\
\hline Ali et al., 2017 & & $\mathrm{x}$ & $\mathrm{x}$ & $\mathrm{x}$ & $\mathrm{x}$ & $\mathrm{x}$ & & $\mathrm{x}$ & & & $\mathrm{x}$ & & & & & & & & \\
\hline Jain et al., 2017 & $\mathrm{x}$ & & & & & $\mathrm{x}$ & & & & & & & & $\mathrm{x}$ & & & & & $\mathrm{x}$ \\
\hline Chowdhury and Quaddus, 2016 & $\mathrm{x}$ & $\mathrm{x}$ & $\mathrm{x}$ & $\mathrm{x}$ & & & & & $\mathrm{x}$ & & & $\mathrm{x}$ & & & & & & & \\
\hline Masood et al, 2016 & & & $\mathrm{x}$ & & & $\mathrm{x}$ & $\mathrm{x}$ & & & & & & & & $\mathrm{x}$ & & & & \\
\hline Scholten and Schilder., 2015 & $\mathrm{x}$ & & & & & & & & & & & & & & & & & & \\
\hline Hohenstein et al., 2015 & $\mathrm{x}$ & $\mathrm{x}$ & $\mathrm{x}$ & $\mathrm{x}$ & & & & & & & & & $\mathrm{x}$ & & & & & & \\
\hline Tukamuhabwa et al., 2015 & $\mathrm{x}$ & $\mathrm{x}$ & $\mathrm{x}$ & & & & & & & & & & & & & & & & \\
\hline Gunasekaran et al., 2015 & $\mathrm{x}$ & $\mathrm{x}$ & $\mathrm{x}$ & $\mathrm{x}$ & $\mathrm{x}$ & $\mathrm{x}$ & & $\mathrm{x}$ & & & & & & & & & & & \\
\hline Day, 2014 & $\mathrm{x}$ & & & $\mathrm{x}$ & $\mathrm{x}$ & & $\mathrm{x}$ & & & & & & $\mathrm{x}$ & & & & & & \\
\hline Dubey et al., 2014 & $\mathrm{x}$ & $\mathrm{x}$ & $\mathrm{x}$ & & & & & & & & & & & & & & & & \\
\hline Scholten et al., 2014 & & $\mathrm{x}$ & & & & & $\mathrm{x}$ & & & & $\mathrm{x}$ & & & & & & & & \\
\hline Hearnshaw and Wilson, 2013 & & & & & & $\mathrm{x}$ & & & & & & & & & & & & & \\
\hline Wieland and Wallenburg, 2013 & & $\mathrm{x}$ & & $\mathrm{x}$ & $\mathrm{x}$ & & & $\mathrm{x}$ & & & & $\mathrm{x}$ & & & & & & & \\
\hline Golgeci and Ponomarov, 2013 & & & & & & & & & & & & & & & & & & $\mathrm{x}$ & \\
\hline Soni and Jain, 2011 & $\mathrm{x}$ & & $\mathrm{x}$ & $\mathrm{x}$ & & $\mathrm{x}$ & & & & & & & & $\mathrm{x}$ & & & & & \\
\hline Jüttner and Maklan, 2011 & $\mathrm{x}$ & $\mathrm{x}$ & $\mathrm{x}$ & $\mathrm{x}$ & & & $\mathrm{x}$ & & & & & & & & & & & & \\
\hline Ponomarov and Holcomb, 2009 & $\mathrm{x}$ & $\mathrm{x}$ & $\mathrm{x}$ & $\mathrm{x}$ & $\mathrm{x}$ & & & $\mathrm{x}$ & $\mathrm{x}$ & & & & & & & $\mathrm{x}$ & & & \\
\hline Christopher and Peck, 2004 & $\mathrm{x}$ & $\mathrm{x}$ & & $\mathrm{x}$ & $\mathrm{x}$ & & & & & & & & & & & & $\mathrm{x}$ & & \\
\hline Total & 14 & 13 & 13 & 12 & 8 & 7 & 6 & 5 & 3 & 2 & 2 & 2 & 2 & 2 & 1 & 1 & 1 & 1 & 1 \\
\hline
\end{tabular}




\subsection{Collaboration in DMSNs}

In a commercial context, supply network collaboration enables resilience (Scholten and Schilder, 2015) which is also essential in DMSNs (Masood et al., 2017; Tang, 2017). In a DMSN, multiple actors are involved in managing a disaster event. However, the complexity of a disaster environment does not necessarily encourage collaboration (Balcik et al., 2010), which continues to be a fundamental weakness of humanitarian organisations. One explanation for this is that DMSN actors have more or less misaligned motivations for being involved in DMOs (Hellingrath et al., 2013) in contrast to CSN where the actors have aligned incentives. Cozzolino (2012) provides an overview of the actors in DMOs through an interconnected humanitarian relationships model, i.e. the government, military, aid agencies, NGOs, logistics, other companies providing essential goods and donors. Apart from the donors, these actors can be summarised into three key sectors, namely the public, socio-civic, and private sectors (Waddell and Brown 1997).

Cao and Zhang (2011) identify supply network collaboration activities as information sharing, goal congruence, decision synchronisation, incentive alignment, resource sharing, and joint knowledge creation. This classification of collaboration activities can be used to identify existing cross-sector collaboration activities within a DMSN.

The general public's perception suggests that the government has the sole responsibility for conducting relief operations while other actors only abide (Balcik et al., 2010). However, public authorities do not usually have all the capacities and resources, especially transportation assets and logistical competence to singlehandedly manage DMOs. Socio-civic organisations, more commonly referred to as non-governmental organisations (NGOs), are regular participants in DMOs as well. Characterised as neither part of a governmental office, nor a business organisation, NGOs provide opportunities for citizens to volunteer in social work and development. NGOs are typically members of international organisations with national chapters in different countries. Such organisations are already used to working hand-in-hand with governments especially when a state of calamity is declared in a disaster-stricken region.

The private sector is defined and characterised by commercial businesses operating for profit. These include firms operating in various sectors providing products and services, e.g. manufacturing, third-party logistics, utilities and the like. Several studies have already explored the role of the private sector in DMOs (Qiao et al., 2010; Koliba et al., 2011; Chen et al., 2013; Izumi and Shaw, 2014; Gabler et al., 2017; Nurmala et al., 2018). Private firms do not only serve their direct customers but also acknowledge their existence as part of a community and a bigger society (Swanson and Smith, 2013).

Wiens et al. (2018) summarise the roles of the above-mentioned key sectors within the DMSN and show that collaboration between the public sector and NGOs has already been established. However, the private sector is found to be providing only occasional support through donations and services as well as acting as a partner in keeping critical infrastructure functioning in case the assets require privatisation.

\subsection{Assessment of DMSNs}

The public sector and humanitarian NGOs are said to be experts in welfare assessment rather than logistics or operations management (Wang et al., 2016). This has inspired several empirical studies exploring existing partnerships between the private sector and the humanitarian sector. Banomyong and Julagasigorn (2017) report on philanthropic collaboration in a situation where a multi-national company provided transportation assets to deliver water filtration equipment sourced by an NGO. Long-term partnerships have also been identified, particularly the "Moving the World" initiative of TNT, a third-party logistics company and World Food Programme (WFP) (Tomasini and Van Wassenhove, 2009). Beyond disaster response, participation of the private sector in disaster preparedness and mitigation phases of the disaster management cycle are also feasible, especially in the fields of construction, infrastructure and telecommunication (Izumi and Shaw, 2014). Although a few good cases of private sector involvement in disaster management have been identified, Nurmala et al. (2018) reveal that most private sector involvement is still limited to philanthropical financial contributions. Masood et al. (2017) introduced the Disaster Resilient Supply Chain Operations (DROPS) Framework (Figure 5) as a result of an EPSRC Global Challenges Research Fund Project including a 5-day international workshop on DROPS involving multi-sectoral humanitarian experts. The DROPS Framework presents many relevant considerations to enable the holistic analysis of a DMO which have not been found in other literature. It proposes that, as a minimum, following the process should be incorporated for building a resilient supply network for DMOs across the disaster management cycle (response-recovery-mitigation-preparedness): conducting requirements analysis (including the identification of requirements for big data analytics), analysing the current practice of DMOs, identifying and analysing DROPS considerations, identifying and analysing DROPS strategies (including disaster big data analytics and integrated SNRES models), and developing a contextualised DROPS model for organisations (Masood et al. 2017). While the DROPS framework (Masood et al, 2017) enables the comprehensive examination of DMOs, the role of cross-sector collaboration in building resilience is yet to be explored. 


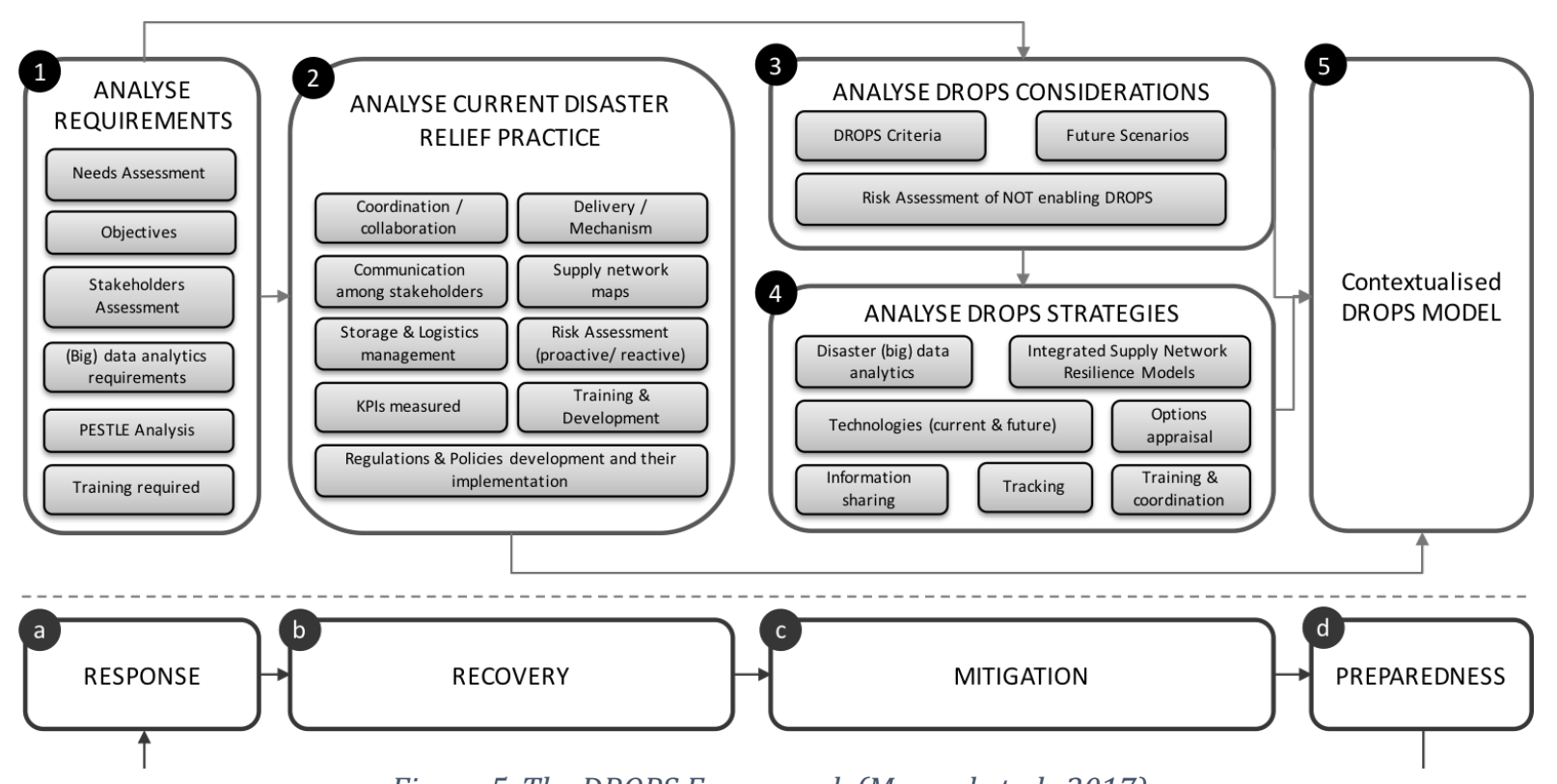

Figure 5. The DROPS Framework (Masood et al., 2017)

\subsection{Research Gaps}

Current literature has established CSN management practices that may be applicable to DMSNs (Van Wassenhove, 2006; Oloruntoba and Gray, 2006; Kovács and Spens, 2007; Balcik et al., 2008). However, building SNRES within the disaster management context has not yet been fully explored. This gap has also been recognised by a number of researchers who have contributed DMSNRES studies in recent years (Masood et al., 2017; Scholten et al., 2014; Day, 2014; Singh et al., 2018; Rasouli, 2019; Dubey et al., 2019).

With the growing size of literature on supply network resilience, collaboration has been identified as among the top enablers of SNRES (see sections 2.1 and 2.2). While a wide variety of studies have focussed on supply network collaboration, there is a lack of literature on how supply network collaboration can influence DMSNRES.

Regarding collaboration within DMSN, the role of the private sector has been discussed in humanitarian partnerships and collaboration literature. However, it has been limited mostly to procurement partnerships, philanthropic involvement such as financial contributions and services offering the transportation of goods between a single private firm and a single NGO. Several authors (Nurmala et al., 2018; Lewin et al., 2018; HELP Logistics et al., 2018) point out this gap and refer to current humanitarian-business partnerships with the potential to go beyond such short-term involvement. Thus, not only is it worth further exploring the potential of cross-sector collaboration in disaster management, but it is also important to start addressing its influence on DMSNRES in disaster management.

\subsection{Research Questions}

Following the research gaps, the main research question (RQ) is:

RQ: How can resilient disaster management supply networks be built through cross-sector collaboration?

To answer the main RQ, the following sub-questions are addressed:

SQ1: How can cross-sector collaboration in DMSNs be analysed from a resilience perspective?

$\mathrm{SQ} 2$ : Where is cross-sector collaboration practiced within the DMSN?

SQ3: What are the implications of existing cross-sector collaboration activities on resilience within

DMSNs?

To address the sub-questions, the following research objectives are achieved:

RO1: Develop a theoretical model than can be used to analyse cross-sector collaboration and its influence on DMSNRES;

RO2: Identify existing cross-sector collaboration activities within each disaster management phase;

RO3: Identify causal relationships between cross-sector collaboration and DMSNRES 


\section{Research Methodology}

A case study approach was the most appropriate research method for this study. The fit of the research question to the research strategy was important in the research strategy selection. Yin (2003) states that case studies are applicable to studies exhibiting the following characteristics: (a) research questions which aim to answer a "How" or "Why" question; (b) behaviours of actors that cannot be manipulated by the researchers; (c) relevant contextual conditions; and (d) boundaries between the phenomenon and context that are unclear. This study examines contemporary phenomena which involve cross-sector collaboration within DMSNs. The case study challenges the common perception of case studies being used only for theory generation. Existing theories and frameworks do exist within supply chain resilience and collaboration literature (Masood, 2017; Scholten and Schilder, 2015), and this research aims to contextualise these theories in relation to DMSNs. Hence, this case study reflects theory elaboration, which sits between theory generation and theory building (Ketokivi and Choi, 2014). At the end of this case study, new insights are propounded, resulting in a new theory or a novel framework in line with Eisenhardt (1989). It is important to note that several research strategies are not mutually exclusive. This case study was facilitated using semi-structured interviews as a key tool for data gathering.

\subsection{Case Study Selection}

In choosing the case to investigate, the authors sought guidance from the Sendai Framework, which emphasises that resilience should be built across international, national and local contexts (UNDRR, 2015). The World Disasters Report 2018 also identifies unaddressed complexities in the global management of disasters and emphasises the need to strengthen domestic DMOs (IFRC, 2018). Natural disasters comprise more than 50\% of total global disasters in terms of occurrence. This increases to more than $99 \%$ in terms of total disaster-affected people globally (CRED, 2019). With these considerations in mind, this study looks specifically at a domestic context in the face of natural disasters.

To ensure significant contribution of the study, the authors isolated the top five countries affected most by natural disasters in the last ten years: the United States, China, the Philippines, India and Indonesia (CRED, 2019). Participation of the countries in UN-led Connecting Business initiatives was preferred to ensure that specific organisations from each of the public, socio-civic and private sectors could be identified. Among these five countries, the Philippines, India and Indonesia were all participants in the UN program. Consequently, these countries ranked the lowest in terms of economic standing based on GDP per capita (IMF, 2019). It has been reported that middle-income countries accumulate higher risks since there is rapid economic growth but the institutional capacity to manage resources does not develop at the same pace (The World Bank, 2017). Hence, this specific study was deemed more relevant to those countries with a lower economic standing. Consequently, the Philippines was selected since relevant contacts in the country were readily available, which were crucial to conducting the case study.

\subsection{The Philippine Disaster Profile}

The Philippines ranked second in terms of the greatest number of people affected by disasters in 2018 (approximately 6.5 million people) (CRED, 2019). Much of the natural disaster risk in the Philippines is due to its geographical profile. The Philippines is situated near the equator, is surrounded by the largest ocean in the world, and forms part of the region with the warmest ocean temperature globally which boosts the formation of typhoons.

Aside from frequent typhoons, the country also experiences earthquakes due to its location at the Pacific Ring of Fire. According to the Philippine Institute of Volcanology and Seismology (PHIVOLCS), there are 23 active volcanoes in the country (PHIVOLCS, 2019). While the occurrence of earthquakes is frequent due to the country's geographical location, damaging earthquakes constitute less than $10 \%$ of the total natural disasters which have occurred in the Philippines during the last ten years (CRED, 2019).

The above facts emphasise the need to properly manage disaster operations in the Philippines. The country's National Disaster Response Plan (NDRP) is headed by the National Disaster Risk Reduction and Mitigation Council (NDRRMC) (NDRRMC Response Cluster, 2016). The Council comprises a chairperson selected by executive heads from various government agencies: disaster prevention and mitigation, disaster preparedness, disaster response, disaster rehabilitation and recovery. The Council is also supported by a number of other government departments, as well as private and civil society organisations.

Under the NDRRMC, smaller and more localised Disaster Risk Reduction and Mitigation Councils (DRRMCs) are organised based on geographical scope (NDRRMC Response Cluster, 2016). The smallest unit of organisation is at a village [barangay] level and consists of a group of households in close proximity to one another. Cities or municipalities are groups of barangays; hence, if multiple barangays are affected by a disaster, the local responsibility lies with city or municipal DRRMCs. The same principle applies to provincial DRRMCs, since the province consists of a group of several cities and municipalities. A region in the Philippine context involves a collection of several provinces. Regional DRRMCs report directly to the NDRRMC. 


\subsection{Data Collection}

Data collection for this study was accomplished using semi-structured interviews. This method allowed for a flexible approach to the interview process while building rapport with respondents. Semi-structured interviews enabled the authors to clarify and probe, which facilitated additional information gathering about their experiences in cross-sector collaboration. While there was flexibility in this data collection method, structure was maintained to avoid divergence from the main research topic (see Appendix A).

Organisations from key sectors were approached: the public sector, socio-civic NGOs, and the private sector. These sectors offered diverse perspectives given the differences in their daily operating environments. The authors purposely selected organisations which already had sufficient experience in Philippine disaster response operations. The respondents' expertise helped to build confidence in the results of the study. The country's NDRP was used to help identify key organisations within each sector.

In the public sector, a governmental department $(\mathrm{C} 1)$ was chosen due to their mandate to lead the disaster response and relief efforts of the country. A national level NGO (C2) was chosen as the agency in the NGO sector since its collaboration with the public sector had already been institutionalised in the NDRP. Moreover, it was the only NGO with a permanent seat in the NDRRMC. Lastly, a national-level private sector disaster resilience organisation, Philippine Disaster Resilience Foundation (PDRF) (C3) was chosen and identified as an emerging private sector network for disaster resilience. It also formed part of the Connecting Business Initiative (CBi), a UN-led private sector network. PDRF is composed of business organisations from eight clusters (power, fuel \& energy, telecommunications, water and sanitation, food and non-food, logistics, medical services, finance, and infrastructure) providing support during disaster operations. PDRF also offers business continuity planning modules for its member companies.

A guide to the interview questions is provided in Appendix A. The organisations interviewed were asked to select a representative actively involved in DMOs for the interview session. The details are provided in Table 6 . The sample includes organisations representing the public, NGO (socio-civic) and private sector. PDRF is the only organisation functioning as an agency/umbrella organisation for private / business organisations in the Philippines. PDRF has extensive knowledge of disaster operations as well as business continuity, with100+ member companies. They hold a lot of information regarding private sector contribution in disaster operations.

Table 6. Details of respondents interviewed in the case study

\begin{tabular}{|l|l|l|l|}
\hline Organisation & Sector & Respondent's Position in the Agency & Experience in DMO \\
\hline C1 & Public & Division Chief- Logistics Management Division & 6 years \\
\hline C2 & $\begin{array}{l}\text { NGO (Socio- } \\
\text { civic) }\end{array}$ & $\begin{array}{l}\text { Logistics officer - Disaster Management } \\
\text { Service }\end{array}$ & 5 years \\
\cline { 3 - 4 } & & Program coordinator - Disaster Response Unit & 6 years \\
\cline { 3 - 4 } & & Program coordinator - Disaster Recovery Unit & 2 years \\
\cline { 3 - 4 } & & $\begin{array}{l}\text { Program coordinator - Disaster Preparedness } \\
\text { Unit }\end{array}$ & 8 years \\
\hline C3 (PDRF) & \multirow{2}{*}{ Private Sector } & Operations Centre Director & 3 years \\
\cline { 3 - 4 } & & Recovery Program Manager & 5 years \\
\cline { 3 - 4 } & & Geohazard and Spatial Information Manager & 3 years \\
\hline
\end{tabular}

The respondents' consent was requested for the interviews to be recorded. For those interviews where approval was not given, the authors opted to take notes instead.

\subsection{Data Analysis}

The DROPS Framework (Masood et al, 2017) was used to analyse cross-sector collaboration with guidance from the supply network collaboration activities identified by Cao and Zhang (2011). An analysis framework based on collaboration and resilience was then developed, which informed the creation of the theoretical model. This was used for data collection and analysis of the case study. Causal relationships were analysed to link cross-sector collaboration activities with the resilience criteria. Patterns were deduced from the analysis which formed the basis of the discussion.

\subsection{Research Methodology Roadmap}

The study's research methodology roadmap is summarised in Figure 6. RO1 was addressed through the case study, involving the development and usage of the theoretical model. RO2 and RO3 were addressed through analysis of the findings from the theoretical model. 

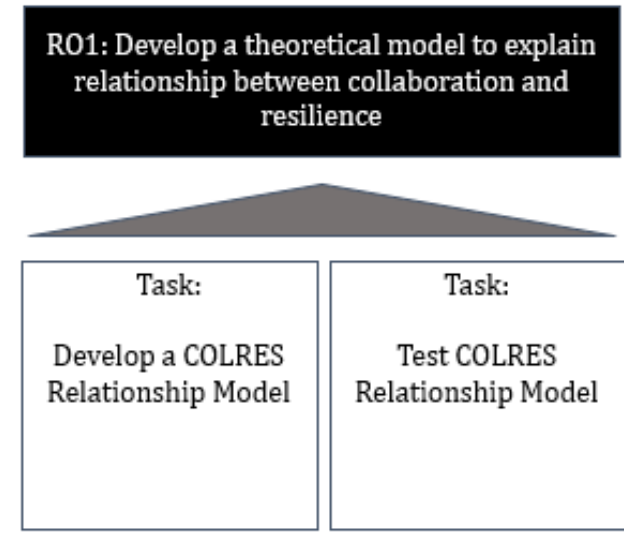

Philippines case study
R02: Identify existing cross-sector collaboration within each disaster management phase

R03: Identify causal relationships between cross-section collaboration and DMSN resilience

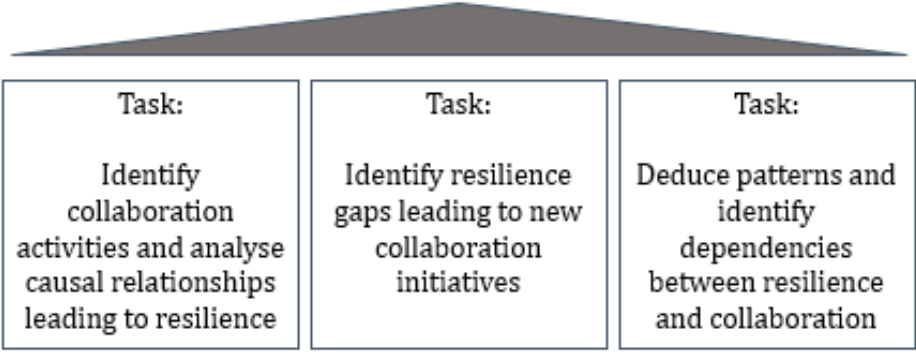

Findings \&

Discussion

Figure 6. Research Methodology Summary

\section{Theoretical Model Development - COLRES Analysis Framework for DMSNs}

A Collaboration-Resilience (COLRES) Analysis Framework for DMSN (Figure 7) was developed based on the DROPS Framework (Masood et al., 2017). Compared to the DROPS framework, which is an exhaustive framework covering all the aspects of disaster management, the COLRES analysis framework only focuses on collaboration and resilience aspects in DMSNs. The discussion in this section forms part of the case study of the Philippines and follows the five main components of the DMSN COLRES analysis framework. It serves as guidance on understanding how resilience is defined within DMSNs (Section 4.3) and how the existing crosssector collaboration activities are characterised in DMSNs (Section 4.4), ultimately generating a COLRES Relationship Model (Section 4.5) which is further applied to the case study in Section 5.

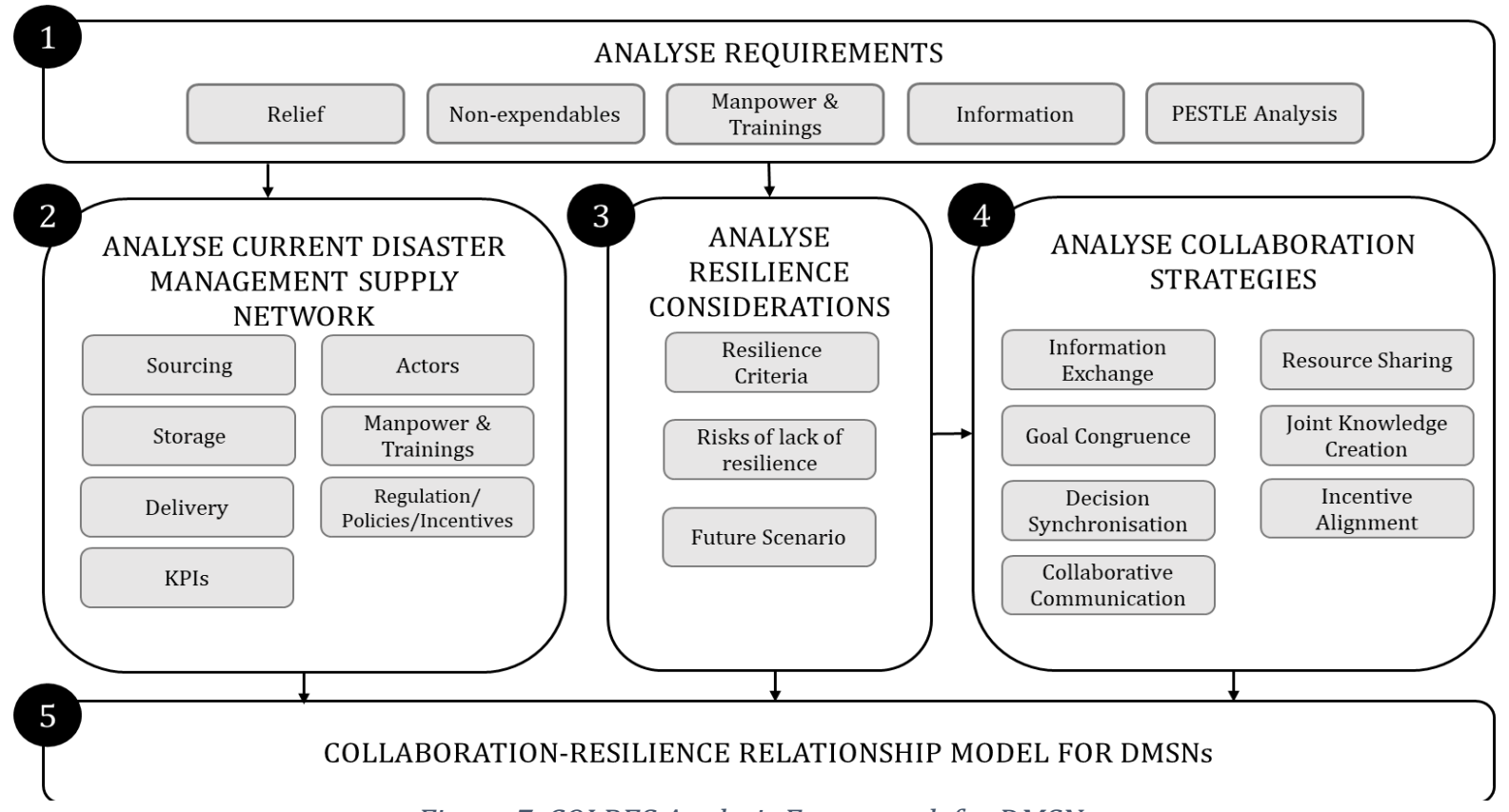

Figure 7. COLRES Analysis Framework for DMSNs

\subsection{Analyse Requirements}

The top resources needed within DMSNs were identified through interviews with the respondents. Relief items were recognised as family food packs, water, and evacuation kits. Beyond the relief items, non-expendable resources to enable better disaster management were found to be necessary as well. These included emergency communication devices, power sources, transportation equipment and infrastructure equipment. Manpower was 
also deemed necessary throughout the whole supply network, including (but not limited to) operations managers, incident commanders, medical responders, relief distribution teams and community volunteers. In addition, reliable information was considered critical in DMSNs as it triggers the movement of resources from one site to another. Since so much information flows through the DMSN in many different directions, the processing of big data into relevant information can enable fast distribution of the right resources at the right location at the right time and in the right quantities.

Aside from assessing immediate resources needed for effective disaster response, specific requirements may be suitable to particular disaster scenarios. A PESTLE (Political, Economic, Sociological, Technological, Legal, Environmental) analysis may help to evaluate the situation on the ground. This is highly relevant to the case of the Philippines where disaster management is very much politically oriented given the responsibilities of government officials to facilitate the whole operation. Economic and social well-being are also gauged in a given disaster scenario to identify interventions that can be provided by the responders.

\subsection{Analyse Current Disaster Management Supply Network}

The process by which the identified resources flow within the DMSN is analysed in this section. During white alert (low risk) status, C1, C2 and C3 all focus their attention on capacity building. Preparation activities, such as procurement and pre-positioning, facilitate faster response when a disaster occurs. Both $\mathrm{C} 1$ and $\mathrm{C} 2$ have their own contract suppliers for relief items. Both practice pre-positioning of items in regional relief warehouses. $\mathrm{C} 1$ concentrates on pre-positioning 30,000 food packs in each of their 16 regional warehouses across the country. C2 also pre-positions evacuation kits in 10 warehouses across the country at varied inventory capacities. As C2 does not have enough warehouses for each of the country's 16 regions, clustering of provinces and regions assigned to each warehouse is commonplace.

The military and third-party logistics (3PL) are able to provide logistical resources such as trucks for relief deliveries. $\mathrm{C} 1$ has pre-arranged agreements with 3PL companies. Ad-hoc participation of private companies deploying their own transportation assets is also observed to augment capacity. C2 has its own logistical resources to transport relief items to disaster sites. Communication means and power sources go hand-in-hand as these are critical utilities that are not only urgently needed by the calamity victims, but also by the first responders on the scene. Like most countries, most of these resources are supplied by private telecommunications and electricity companies regulated by the government. Figure 8 provides an overview of resource flows in DMSN in the Philippines. It specifically focuses on the supply flow for the top resources identified in Section 4.1: power, communication, logistics \& infrastructure, relief and medicines. The supply network shows which nodes are privately-owned, also demonstrating the integral role of the private sector in the DMSN.

When a disaster occurs, the NDRP is activated to provide general direction for all government agencies and networks involved in NDRRMC. An incident command system (ICS) is set up based on the scope of impact of the disaster and is the main coordinating body in command, responsible for managing all operations on the affected site. All response teams on the disaster site must report to the ICS. Figure 9 summarises information flows within the disaster supply network. 


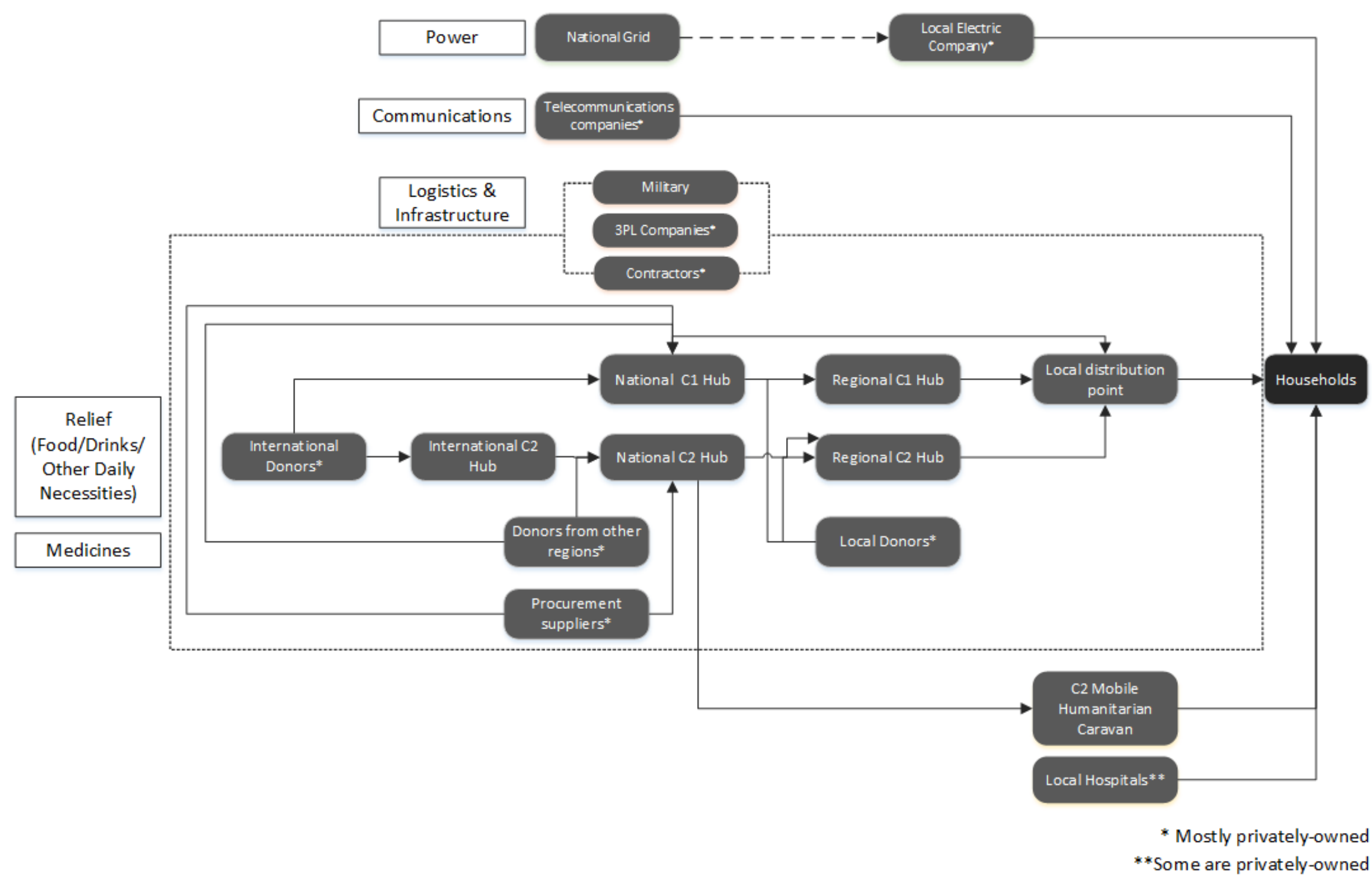

Figure 8. Resource Flows in the Philippine DMSN 


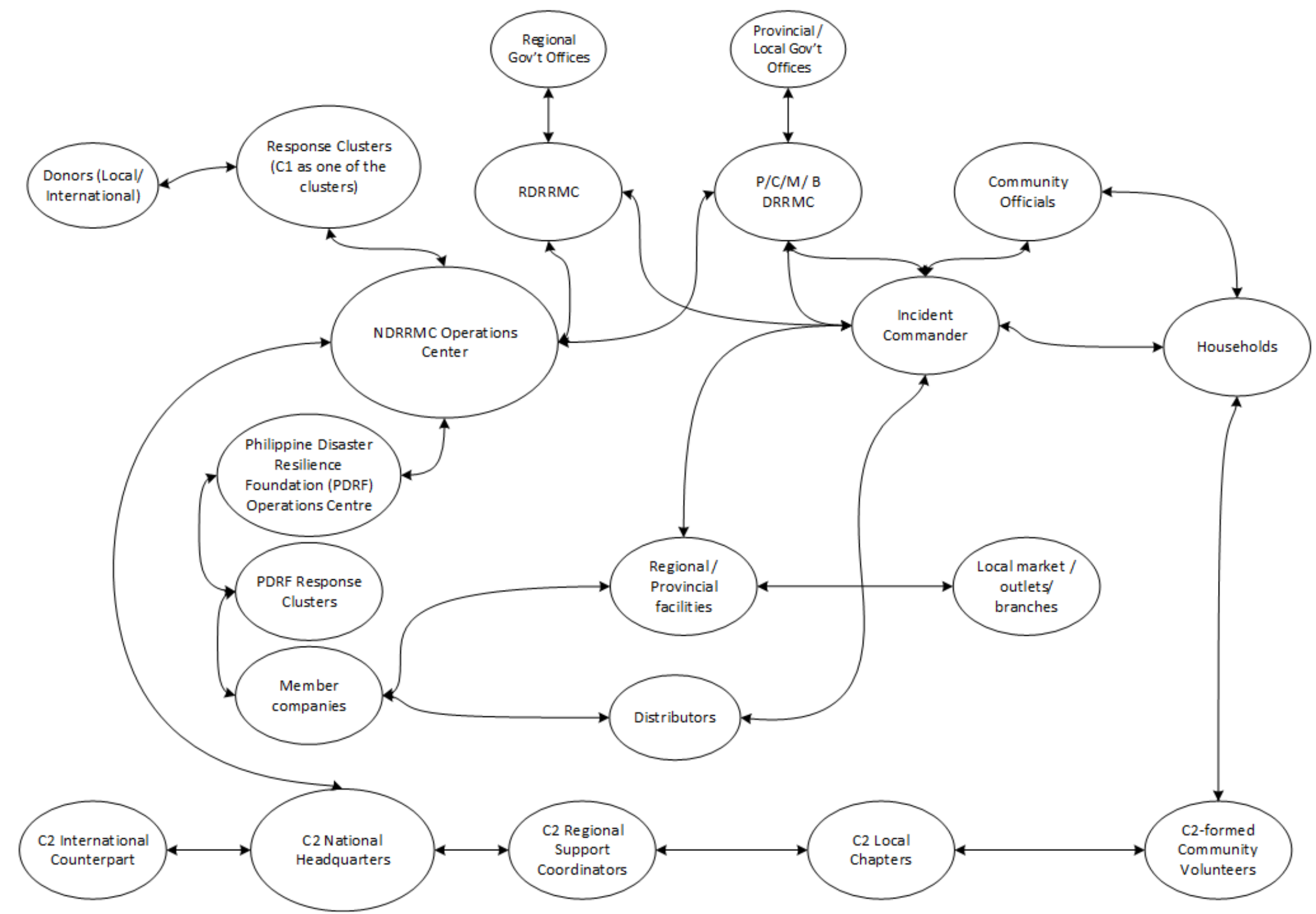

Figure 9. Information flows in the Philippine DMSN 


\subsection{Analyse Resilience Considerations}

\subsubsection{Resilience Criteria}

By analysing DMSNRES considerations, the authors developed DMSNRES criteria with which cross-sector collaboration activities can be associated. The structured literature review on SNRES identified the top enablers of SNRES (Table 5). This study adopted the finding of Scholten and Schilder (2015) that flexibility, visibility and velocity are the first-order enablers of resilience, and collaboration is an antecedent of these three. These constructs are defined in Table 4 and respondents were asked to identify the DMSN capabilities which characterise each construct.

a) Flexibility

Sourcing Redundancy - DMSNs rely on multiple sources that can provide critical resources at the earliest possible time. Given the unpredictability factor in DMSNs, the availability of back-up suppliers is of high importance.

b) Visibility

Information Reliability - A DMSN is characterised by sporadic information flow. Hence, addressing this complexity enables the resilience of the DMSN. Factual information is supported by available technology providing (big) data such as forecasts, damage estimates, population count, and other analytical information needed for informed decision-making

c) Velocity

Responsiveness - A response is expected to arrive within 72 hours after a disaster event. It may also refer to faster return to normalcy.

d) Robustness Disaster management experts describe robustness as the ability of a community to sustain damages and is characterised by:

Capacity Building - Owing to the archipelagic geography of the Philippines, relief items may need to be transported by sea or air for inter-island relief operations which may require high costs or long lead times. This can be characterised by local availability of critical resources and skilled human resources.

The resilience criteria (a-c) mostly define characteristics of an agile supply network. According to Cozzolino et al. (2012), the agile strategy applies mostly to immediate response, enabling fast reactive solutions. An additional resilience criterion to represent DMSN performance during proactive stages was deemed suitable as this study is not only limited to disaster response. Robustness (d) was identified in the literature as pertaining to proactive resilience (Välikangas, 2010; Durach et al., 2015) and was used as an additional resilience criterion for DMSNs.

\subsubsection{Consequences of not practicing DMSNRES}

The lack of prioritisation of DMSNRES can lead to repercussions in terms of operational costs, economic damages, injuries and lost lives. Respondents were asked to recall scenarios where response was very challenging to manage. All of the respondents recalled the disarray they experienced during Typhoon Yolanda (Haiyan) in 2013. The challenges cited by the respondents are summarised as follows:

1. There were no formalised triggers for national government intervention, and thus the local communities felt neglected by the delayed response of the national government;

2. Unaligned knowledge between the local government and the international humanitarian cluster system led to disorganised operations on the ground;

3. The proliferation of non-standardised needs assessment for targeted planning led to multiple assessments conducted by each NGO, which induced indifference of the victims;

4. The private sector and other NGOs preferred to work independently, bypassing Local Government Units (LGUs) and local DRRMCs, resulting in poor monitoring of the relief distribution.

\subsubsection{Potential Future Scenario}

Six years after Typhoon Yolanda, many lessons learnt were applied especially to coordination and preparation measures in the Philippines. However, as with any operation, vulnerabilities still exist within the Philippine DMSN. Assessing the current DMSNRES against a potential future scenario unravels resilience gaps which can be the basis for resilience improvements in the Philippines. A future scenario identified by the Metropolitan Manila Earthquake Impact Reduction Study (MMEIRS) is deemed by experts as a worst-case natural disaster scenario for the Philippines. In particular, the Model 8 simulation, which is the potential rupture of the West Valley Fault (WVF) (Figure 10) is highlighted in the MMEIR study. This rupture is estimated to induce a 7.2 magnitude earthquake, marked by local media outlets as "The Big One" or the "mega-earthquake". As the WVF traverses seven out of 16 cities within the Metropolitan Manila, the scenario is considered the worst case in terms of damage. Furthermore, population density may contribute to the severity of the damage given that two of the world's most densely populated city are located within Metropolitan Manila. Based on historical 
earthquake scenarios and a census of the population, the MMEIRS estimates a total of 34,000 casualties (JICA et al., 2004).

Three key scenarios are emphasised in MMEIRS, should the rupture of the WVF occur:

1. Possible splitting of the region into four divisions: MM West, MM East, MM North and MM South (Figure 10); MM West isolated by fire;

2. 1,200,000 people losing their residential homes and 34,000 people losing their lives; and

3. $11 \%$ heavily damaged or collapsed mid-rise buildings; $2 \%$ heavily damaged or collapsed high-rise buildings.

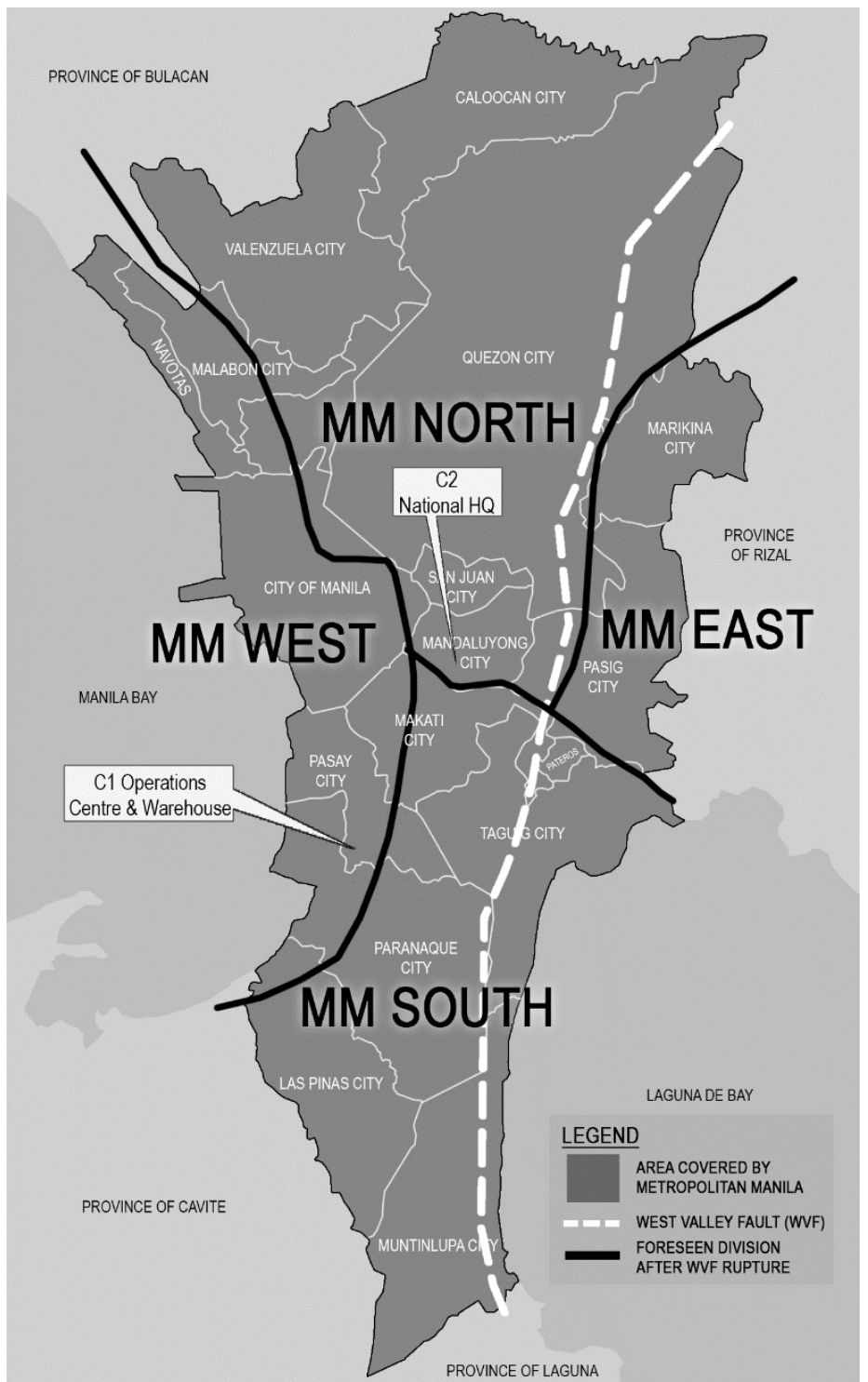

Figure 10. Map of Metropolitan Manila and nearby provinces (Credit: background map contains Philippine Coast and Geodetic Survey data (P.C.G.S, 1988)

\subsection{Analyse Collaboration Strategies}

The collaboration activities were based on the study by Cao and Zhang, (2011). Each collaboration type was defined for the respondents. In turn, characteristics of each type were identified from the interviews through the lens of disaster management.

- Collaborative communication and information sharing both pertain to sharing relevant information and message transmission. Hence, both types are characterised in subsequent sections as information sharing. This type of collaboration is characterised by situational alerts before, during, and after a disaster and the formation of collaborative councils aimed at alignment and joint strategy development. 
- Goal congruence and incentive alignment both pertain to activities where collaborators are in either win-win situations (both experience benefits from the project) or risk-sharing situations. Both collaboration types are therefore characterised in subsequent sections as incentive alignment.

- Decision Synchronisation refers to how collaborators in the supply network are able to collectively align their decisions. This may correspond to collectively developing standard guides or contingency plans.

- Joint Knowledge Creation refers to supply network actors engaging in collaborative learning activities. In a disaster context, this may include skills and process training as well as knowledge exchange workshops aimed at identifying best practices.

- Resource Sharing refers to leveraging capabilities and assets of supply network collaborators. In disaster contexts, this is characterised by making financial donations, sending human resources to help on the ground or in relief warehouses, or offering an organisation's own products and services to address the needs of the DMSN.

\subsection{COLRES Model for DMSNs}

Informed by the preceding analysis, a DMSN Collaboration-Resilience (COLRES) Relationship Model (Figure 11) was developed with the aim of answering the main research question, "How can resilience be built in DMSNs through cross-sector collaboration?". The application of the model involves two parts:

(1) The identification of collaboration activities between the private sector and humanitarian actors that translate into several outcomes for the DMSN, particularly relating to the resilience criteria and the development of DMSNRES;

(2) The assessment of the DMSN against a disaster event where resilience gaps are revealed and can be inputted as new opportunities for collaboration. The DMSN COLRES Model incorporates resiliencebuilding as a continuous process rather than a one-off experience.

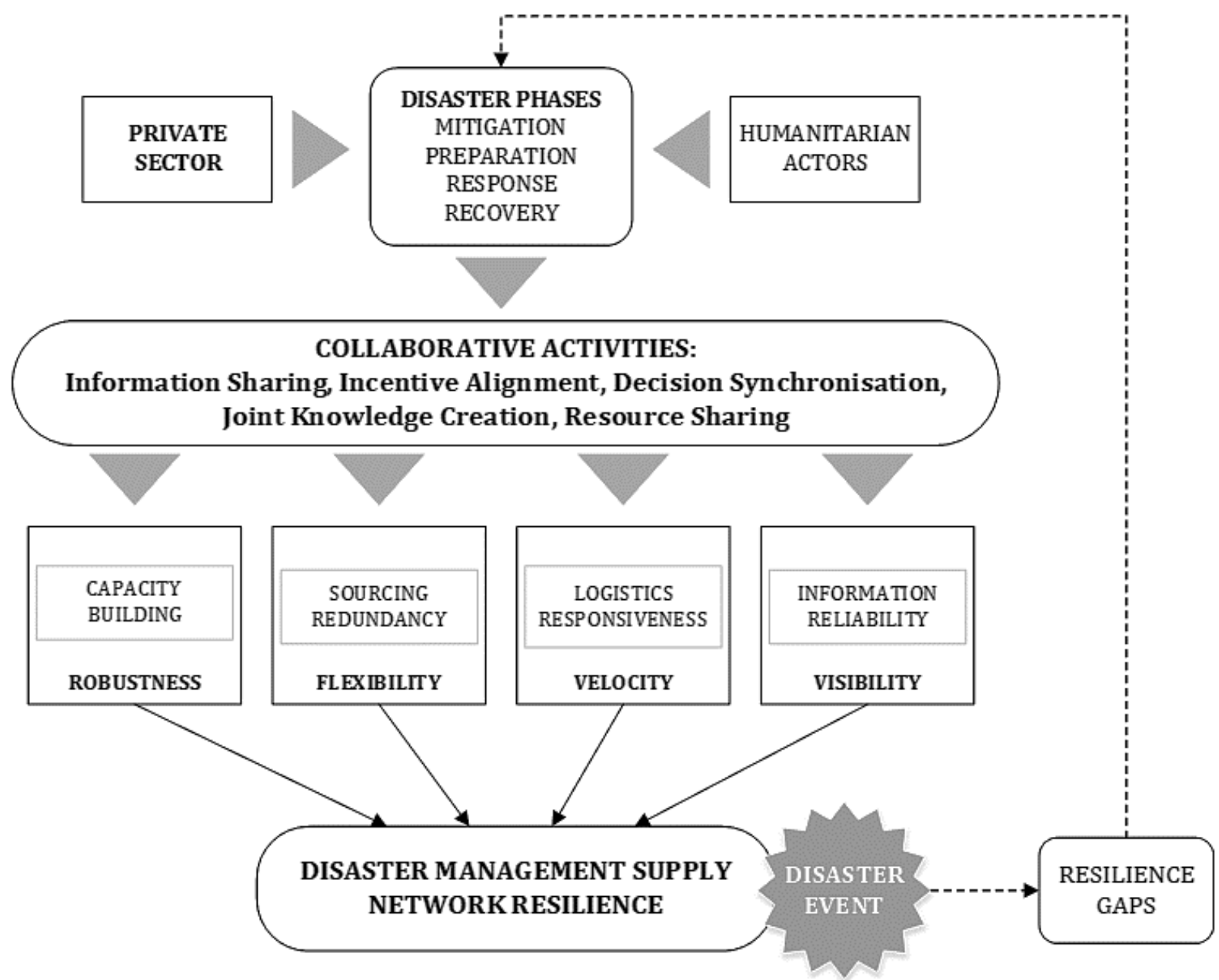

Figure 11. COLRES Relationship Model for DMSNs 
This collaboration-resilience relationship model was validated and used for further data collection and analysis in the case study of the Philippines' disaster management operations. Causal relationships were analysed to link cross-sector collaboration activities and the resilience criteria. Patterns were deduced from the analysis which form the basis of discussion.

\section{Case Study Findings}

The DMSN COLRES Relationship Model was applied to the Philippine's DMSN as an analytical tool. Respondents (listed in Table 6) were asked to identify specific cross-sector collaboration activities exhibiting private sector involvement in the DMSN identified in each disaster management phase - mitigation, preparation, response and recovery (using guide questions provided in Appendix A). Additional collaboration activities were identified from published articles and reports (ILO, 2015; PDRF, 2019). Each activity was classified according to the collaboration types defined in the DMSN COLRES Model. Direct outcomes of each collaboration activity were also identified during interviews with respondents. Each outcome was classified into a generalised outcome based on the DMSN capabilities to which it related the most (i.e., capacity building, sourcing redundancy, information reliability, and logistics responsiveness). These DMSN capabilities were finally linked to the resilience criteria that best characterised the benefits of the activities. The results of this analysis are presented in Table 7. 
Table 7 - Collaboration-Resilience Relationship Analysis

Collaboration Types: DS- Demand Synchronisation; JKC - Joint Knowledge Creation; IA - Incentive Alignment; IS - Information Sharing; RS- Resource Sharing

\begin{tabular}{|c|c|c|c|c|c|c|}
\hline $\begin{array}{l}\text { Disaster management } \\
\text { phase }\end{array}$ & No. & Collaboration Activity & Collaboration Outcome & Collaboration Type & Generalised outcome & Resilience Criteria \\
\hline \multirow[t]{11}{*}{ Mitigation } & 1 & $\begin{array}{l}\text { Co-development of MSME guide to disaster } \\
\text { response by Department of Trade and Industry and } \\
\text { Philippine Chamber of Commerce and Industry }\end{array}$ & Standardised preparedness measures & DS & Capacity Building & Robustness \\
\hline & 2 & $\begin{array}{l}\text { Development of "Katatagan (Strength) in a Box" - } \\
\text { BCP Mobile App }\end{array}$ & $\begin{array}{l}\text { Wider access to business continuity } \\
\text { planning }\end{array}$ & DS & Capacity Building & Robustness \\
\hline & 3 & Updated National Energy Contingency Plan & Less disruption in energy supply chain & DS & Capacity Building & Robustness \\
\hline & 4 & Development of Resiliency Compliance Plan & Less disruption in energy supply chain & DS & Capacity Building & Robustness \\
\hline & 5 & $\begin{array}{l}\text { Knowledge exchange: Connecting Business } \\
\text { Initiative (CBi) private sector networks }\end{array}$ & $\begin{array}{l}\text { Improved disaster management } \\
\text { practices }\end{array}$ & JKC & Capacity Building & Robustness \\
\hline & 6 & Commercial supply chain resilience workshops & $\begin{array}{l}\text { Reduction of vulnerabilities in } \\
\text { commercial operations }\end{array}$ & $\mathrm{JKC}$ & Capacity Building & Robustness \\
\hline & 7 & Public service resilience workshops & $\begin{array}{l}\text { Reduction of vulnerabilities in } \\
\text { government operations }\end{array}$ & JKC & Capacity Building & Robustness \\
\hline & 8 & $\begin{array}{l}\text { Community-based disaster risk reduction (DRR) } \\
\text { and management }\end{array}$ & $\begin{array}{l}\text { Reduction of vulnerabilities in the } \\
\text { community }\end{array}$ & DS & Capacity Building & Robustness \\
\hline & 9 & $\begin{array}{l}2019 \text { National Summit on Strengthening Disaster } \\
\text { Resilience for MSMEs }\end{array}$ & Execution of best practices & JKC & Capacity Building & Robustness \\
\hline & 10 & $\begin{array}{l}\text { Participatory 3D mapping - private sector and } \\
\text { barangay }\end{array}$ & $\begin{array}{l}\text { Reduction of vulnerabilities within the } \\
\text { community; faster recovery of } \\
\text { community means faster recovery of the } \\
\text { company }\end{array}$ & IA & Capacity Building & Robustness \\
\hline & 11 & Company employee trainings on preparedness & $\begin{array}{l}\text { Reduction of vulnerabilities on } \\
\text { household level }\end{array}$ & JKC & Capacity Building & Robustness \\
\hline \multirow[t]{4}{*}{ Preparation } & 12 & $\begin{array}{l}\text { Project AGOS: improving disaster communications } \\
\text { systems of LGUs }\end{array}$ & $\begin{array}{l}\text { More reliable communication } \\
\text { mechanisms at local level }\end{array}$ & IA & Info Reliability & Visibility \\
\hline & 13 & $\begin{array}{l}\text { A-PAD PH: Multi-sectoral platform for } \\
\text { coordination for pooling of efforts at regional level }\end{array}$ & $\begin{array}{l}\text { Increased local capacity within the } \\
\text { region }\end{array}$ & IS & Capacity Building & Robustness \\
\hline & 14 & $\begin{array}{l}\mathrm{C} 1 \text { and } \mathrm{C} 3 \text { memorandum of agreement for disaster } \\
\text { response }\end{array}$ & $\begin{array}{l}\text { Back-up sources augmenting the } \\
\text { capacity of the government }\end{array}$ & IA & Redundancy & Flexibility \\
\hline & 15 & $\begin{array}{l}\text { Online journalism platform initiated collaborative } \\
\text { platform using mobile and web technologies and } \\
\text { social media }\end{array}$ & $\begin{array}{l}\text { Households able to broadcast real-time } \\
\text { situations }\end{array}$ & IS & Responsiveness & Velocity \\
\hline
\end{tabular}


Table 7 (cont'd) - Collaboration-Resilience Relationship Analysis

Collaboration Types: DS- Demand Synchronisation; JKC - Joint Knowledge Creation; IA - Incentive Alignment; IS - Information Sharing; RS- Resource Sharing

\begin{tabular}{|c|c|c|c|c|c|c|}
\hline $\begin{array}{l}\text { Disaster management } \\
\text { phase }\end{array}$ & No. & Collaboration Activity & Collaboration Outcome & Collaboration Type & Generalised outcome & $\begin{array}{l}\text { Resilience } \\
\text { Criteria }\end{array}$ \\
\hline \multirow[t]{6}{*}{ Preparation } & 16 & $\mathrm{C} 3$ participation in local government DRRMC & $\begin{array}{l}\text { Private sector inclusion in disaster } \\
\text { preparedness especially in cities with } \\
\text { CBDs }\end{array}$ & IS & Capacity Building & Robustness \\
\hline & 17 & $\mathrm{C} 1$ procurement for family food packs & $\begin{array}{l}\text { Push-button activation of production } \\
\text { line for family food pack components; } \\
\text { in pre-positioned warehouses }\end{array}$ & IA & Responsiveness & Velocity \\
\hline & 18 & $\mathrm{C} 2$ procurement of evacuation kits & $\begin{array}{l}\text { Ensured quality of kits procured; stock- } \\
\text { piling enabled in prepositioned } \\
\text { warehouses before the disaster event }\end{array}$ & IA & Responsiveness & Velocity \\
\hline & 19 & C2 local procurement of disaster site's local market & Co-location sourcing & IA & Responsiveness & Velocity \\
\hline & 20 & $\begin{array}{l}\text { Situational advisories to } \mathrm{C} 3 \text { member companies for } \\
\text { internal preparedness }\end{array}$ & $\begin{array}{l}\text { Timely activation of disaster } \\
\text { preparedness plans for the welfare of the } \\
\text { employees \& company }\end{array}$ & IS & Responsiveness & Velocity \\
\hline & 21 & $\begin{array}{l}\text { Situational advisories to } \mathrm{C} 3 \text { member companies for } \\
\text { response }\end{array}$ & Faster response to needs on the ground & IS & Responsiveness & Velocity \\
\hline \multirow[t]{3}{*}{ Response } & 22 & $\begin{array}{l}\text { Creation of clusters within } \mathrm{C} 3 \text {, aligned with } \\
\text { NDRRMC clusters and UN clusters }\end{array}$ & $\begin{array}{l}\text { Faster coordination and decision making } \\
\text { and relevant information sharing }\end{array}$ & IS & Responsiveness & Velocity \\
\hline & 23 & C3 EOC: the first-ever private sector-led EOC & $\begin{array}{l}\text { Quality in data analytics supporting fact- } \\
\text { based decision making }\end{array}$ & IA & Info Reliability & Visibility \\
\hline & 24 & Post-disaster coordination meetings in NDRRMC & $\begin{array}{l}\text { Alignment of action plans resulting to } \\
\text { reduced redundancy of efforts }\end{array}$ & IS & Info Reliability & Visibility \\
\hline
\end{tabular}


Table 7 (cont'd) - Collaboration-Resilience Relationship Analysis

Collaboration Types: DS- Demand Synchronisation; JKC - Joint Knowledge Creation; IA - Incentive Alignment; IS - Information Sharing; RS- Resource Sharing

\begin{tabular}{|c|c|c|c|c|c|c|}
\hline $\begin{array}{l}\text { Disaster management } \\
\text { phase }\end{array}$ & No. & Collaboration Activity & Collaboration Outcome & Collaboration Type & Generalised outcome & Resilience Criteria \\
\hline \multirow[t]{9}{*}{ Response } & 25 & Revival of the Philippine Cash Working Group & $\begin{array}{l}\text { Alignment of action plans resulting in } \\
\text { reduced redundancy of efforts }\end{array}$ & IS & Info Reliability & Visibility \\
\hline & 26 & $\begin{array}{l}\text { Financial companies pool funds for humanitarian } \\
\text { organisations }\end{array}$ & $\begin{array}{l}\text { Flexibility in the kinds of interventions } \\
\text { that can be bought/done }\end{array}$ & IA & Redundancy & Flexibility \\
\hline & 27 & $\begin{array}{l}\text { Electric company provides generator sets, } \\
\text { floodlights and heavy equipment for search and } \\
\text { rescue; Jollibee Foods Corporation and McDonalds } \\
\text { Philippines supplies food packs for rescuers; } \\
\text { Pilipinas Shell Petroleum Corporation provides fuel } \\
\text { for generator sets; Makati Development } \\
\text { Corporation's provision of structural engineers }\end{array}$ & $\begin{array}{l}\text { Multiple sources of critical items for } \\
\text { response }\end{array}$ & RS & Redundancy & Flexibility \\
\hline & 28 & $\begin{array}{l}\text { Damage assessment equipment such as helicopters } \\
\text { from private companies }\end{array}$ & $\begin{array}{l}\text { Multiple sources of critical items for } \\
\text { response }\end{array}$ & RS & Info Reliability & Visibility \\
\hline & 29 & $\begin{array}{l}\text { Emergency telecommunications resources from } \\
\text { telecommunications companies }\end{array}$ & $\begin{array}{l}\text { Enabled transfer of information from the } \\
\text { ground }\end{array}$ & RS & Info Reliability & Visibility \\
\hline & 30 & $\begin{array}{l}\text { Ten UPS and NLEX trucks deliver C1 family food } \\
\text { packs to Typhoon Ompong (Mangkhut) victims }\end{array}$ & Faster delivery of relief items & RS & Responsiveness & Velocity \\
\hline & 31 & $\begin{array}{l}\text { Mall opens for temporary shelter; elevated parking } \\
\text { spaces made available for flood avoidance }\end{array}$ & $\begin{array}{l}\text { Make-shift evacuation shelters made } \\
\text { available }\end{array}$ & RS & Redundancy & Flexibility \\
\hline & 32 & A telecom and anti-hunger NGO deliver food packs & $\begin{array}{l}\text { Multiple sources of critical items for } \\
\text { response }\end{array}$ & RS & Redundancy & Flexibility \\
\hline & 33 & $\begin{array}{l}\text { A telecom deploys instant network units in Batanes } \\
\text { and Cagayan }\end{array}$ & $\begin{array}{l}\text { Enabled transfer of information from the } \\
\text { ground }\end{array}$ & RS & Info Reliability & Visibility \\
\hline
\end{tabular}


Table 7 (cont'd) - Collaboration-Resilience Relationship Analysis

Collaboration Types: DS- Demand Synchronisation; JKC - Joint Knowledge Creation; IA - Incentive Alignment; IS - Information Sharing; RS- Resource Sharing

\begin{tabular}{|c|c|c|c|c|c|c|}
\hline $\begin{array}{l}\text { Disaster management } \\
\text { phase }\end{array}$ & No. & Collaboration Activity & Collaboration Outcome & Collaboration Type & Generalised outcome & Resilience Criteria \\
\hline \multirow[t]{5}{*}{ Response } & 34 & $\begin{array}{l}\text { A mall opens for assistance to nearby residential } \\
\text { communities by providing temporary evacuation } \\
\text { with in-house clinics }\end{array}$ & $\begin{array}{l}\text { Faster evacuation and urgent medical } \\
\text { attention }\end{array}$ & RS & Responsiveness & Velocity \\
\hline & 35 & $\begin{array}{l}\text { Mall sends mobile clinic to Villamor Airbase } \\
\text { during Typhoon Haiyan, attending to victims } \\
\text { airlifted from Tacloban to Manila }\end{array}$ & $\begin{array}{l}\text { Faster support for medical needs; no } \\
\text { need to travel to hospital }\end{array}$ & RS & Responsiveness & Velocity \\
\hline & 36 & Donations from several private stakeholders & $\begin{array}{l}\text { Multiple sources of critical items for } \\
\text { response }\end{array}$ & RS & Redundancy & Flexibility \\
\hline & 37 & Needs assessment participation - manpower & $\begin{array}{l}\text { Faster accomplishment of needs } \\
\text { assessment; more details gathered }\end{array}$ & RS & Info Reliability & Visibility \\
\hline & 38 & $\begin{array}{l}\text { C2 partnership with tech company for rapid } \\
\text { geological assessment through drones }\end{array}$ & $\begin{array}{l}\text { Rapid assessment of far-flung areas } \\
\text { which cannot be easily reached }\end{array}$ & RS & Responsiveness & Velocity \\
\hline \multirow[t]{8}{*}{ Recovery } & 39 & $\begin{array}{l}\text { NGOs sends money to } \mathrm{C} 3 \text { to fund rebuilding } \\
\text { projects rather than work through more } \\
\text { bureaucratic structure }\end{array}$ & $\begin{array}{l}\text { Faster execution of plans; skip } \\
\text { bureaucracy }\end{array}$ & IA & Responsiveness & Velocity \\
\hline & 40 & $\begin{array}{l}\text { Manila-based electric company's restoration of } \\
\text { power in Batanes - sending of skilled technicians }\end{array}$ & $\begin{array}{l}\text { Support the incapacity of the local area } \\
\text { to return to normalcy }\end{array}$ & RS & Redundancy & Flexibility \\
\hline & 41 & $\begin{array}{l}\text { Manila-based electric company's restoration of } \\
\text { power in Batanes - sending of skilled technicians }\end{array}$ & $\begin{array}{l}\text { Local electric cooperative technicians } \\
\text { indirectly learning new skills and } \\
\text { adapting new ways to work from } \\
\text { Meralco's team of engineers }\end{array}$ & $\mathrm{JKC}$ & Capacity Building & Robustness \\
\hline & 42 & $\begin{array}{l}\text { Joint effort to replant mangroves in Roxas City - } \\
\text { sending manpower }\end{array}$ & Building back better for the community & RS & Capacity Building & Robustness \\
\hline & 43 & $\begin{array}{l}\text { Pooling of funds for new relocation facility for the } \\
\text { victims of Typhoon Yolanda (Haiyan) }\end{array}$ & Building back better for the community & IA & Capacity Building & Robustness \\
\hline & 44 & $\begin{array}{l}\text { Early recovery assistance for recovery of women's } \\
\text { livelihood in Itogon, Benguet }\end{array}$ & Building back better for the community & IS & Capacity Building & Robustness \\
\hline & 45 & $\begin{array}{l}\text { Consultation workshop on recovery and } \\
\text { rehabilitation from the M6.1 earthquake in Central } \\
\text { Luzon }\end{array}$ & Building back better for the community & JKS & Capacity Building & Robustness \\
\hline & 46 & $\begin{array}{l}\text { C2 \& a private company collaborating to apply } \\
\text { recovery strategies in the workplace in } 2016\end{array}$ & $\begin{array}{l}\text { Reduced vulnerabilities in the } \\
\text { workplace }\end{array}$ & JKS & Capacity Building & Robustness \\
\hline
\end{tabular}




\subsection{Cross-sectoral Collaboration and Resilience}

The results were plotted in graphs which show the relationships between the collaboration types and the resilience criteria. However, the analysis of the relationship of a disaster management phase with both collaboration types and resilience criteria can also provide new insights. Phase and collaboration relationships were plotted, as shown in Figure 12.

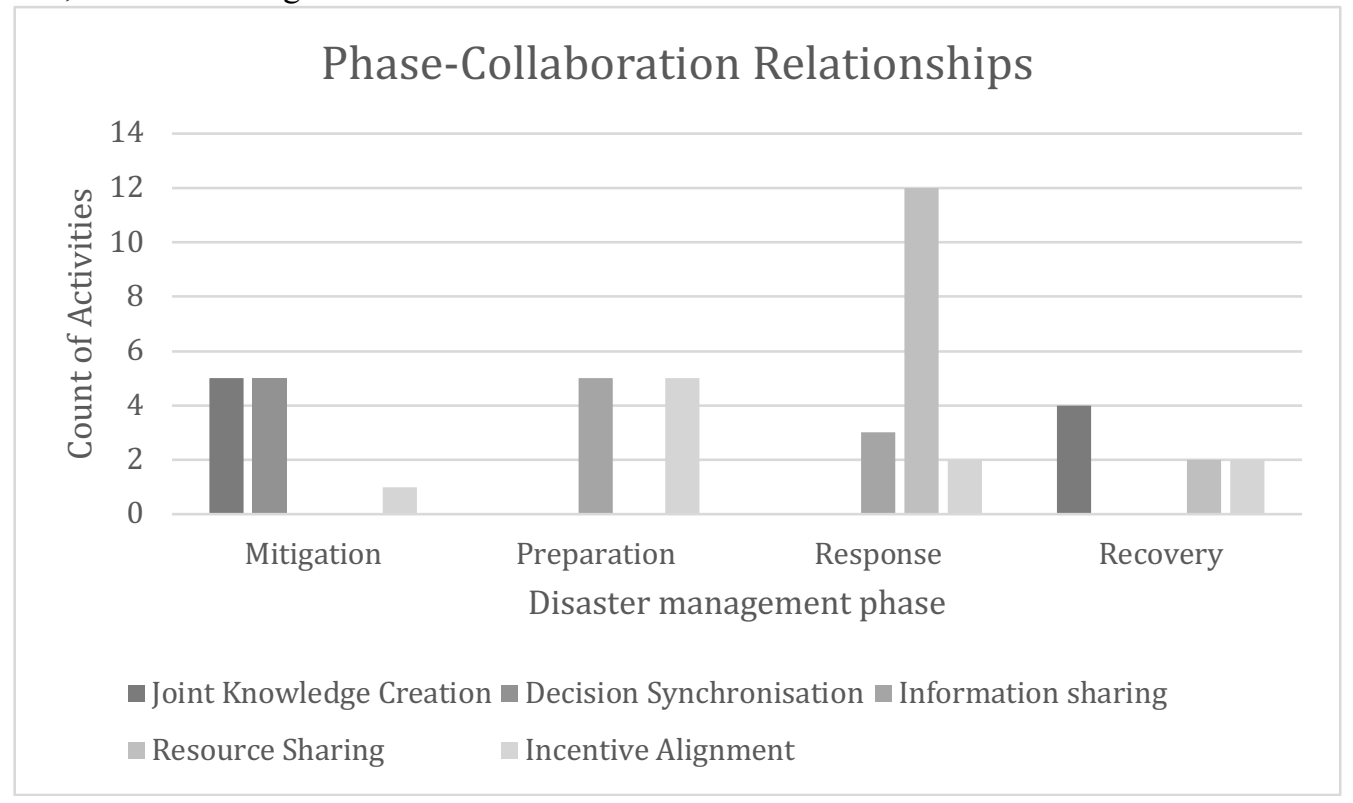

Figure 12. Collaboration activities in different disaster management phases

In the mitigation phase, most collaboration activities were related to decision synchronisation (DS) and joint knowledge creation (JKC). Activities under DS were characterised by the co-development of standards and contingency plans which relevant organisations could use to prepare for disasters. Workshops were usually the activities under JKC in the mitigation phase, characterised by SNRES training and public service continuity training. Within the preparation phase, incentive alignment (IA) and information sharing (IS) were mostly observed. These are characterised by agreements such as procurement partnerships and regular coordination meetings between organisations in different sectors.

Within the response phase, resource sharing (RS) was noticeably common. Private companies provided their core resources, such as generator sets from electric companies, fuel from an oil and gas company, food packs from chains of restaurants, and trucks for the delivery of relief items from third-party logistics providers. All these resource provisions from the private sector were made possible by activities effectively coordinated by the umbrella organisation, PDRF, and its emergency operations centre. In the recovery stage, JKC was common through livelihood training for the community in collaboration with private enterprises and the LGU.

Consultation workshops between the private sector, LGU and NGOs for the joint development of recovery strategies were also held.

The resilience constructs built by collaboration activities with each disaster phase are shown in Figure 13. It was found that especially in the mitigation phase, collaboration activities were mostly for the purpose of capacity building and therefore influenced mostly the resilience criteria of robustness. The preparation phase had a good mix of initiatives to increase DMSNRES through velocity and robustness. These included activities to enable faster response such as pre-positioning and co-location sourcing. Many collaboration activities that addressed visibility, flexibility and velocity were noticeably related to disaster response. Collaboration activities inducing robustness were found within the recovery phase. This is because the main objective within this phase is to "build back better" by not only restoring normal life in the communities, but also by further reducing vulnerabilities. 


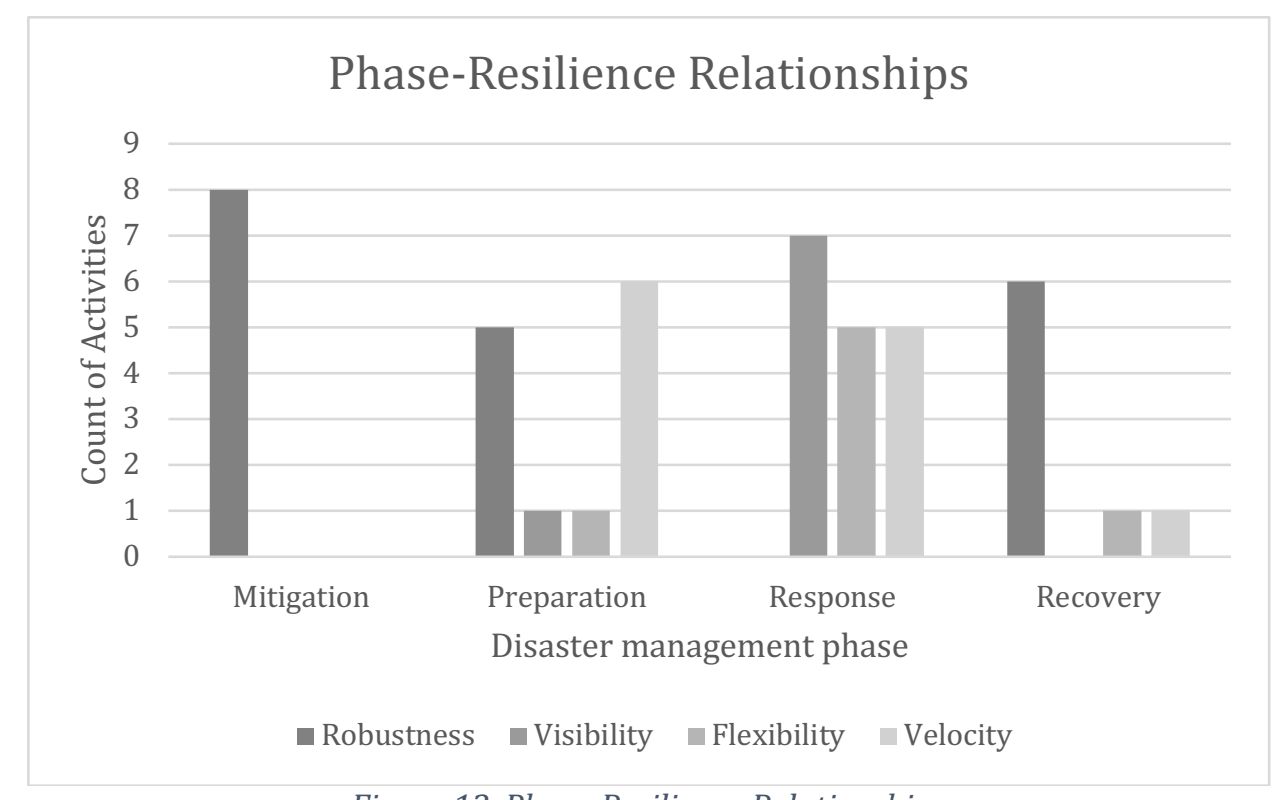

Figure 13. Phase-Resilience Relationships

Finally, to relate the collaboration activities to resilience building, the results were plotted as presented in Figure 14. Evidently, a collaboration type does not exclusively influence only one resilience criterion.

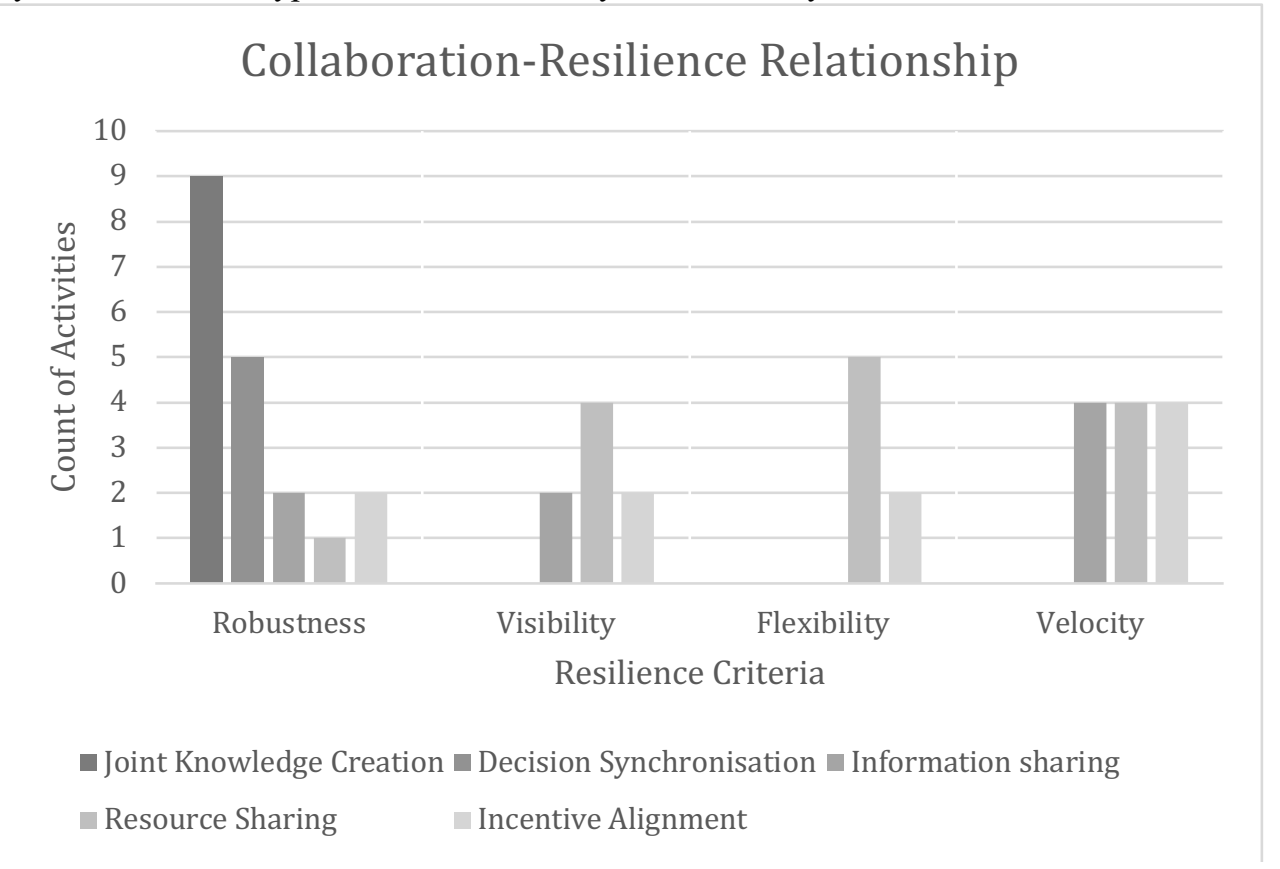

Figure 14. Collaboration-Resilience Relationship

JKC and DS were found to influence robustness the most. JKC and DS were characterised by capacity building through knowledge exchanges in skills training, the standardisation of processes, and the updating of contingency plans to reduce overall disruption within the DMSN. Outcomes of these activities helped build capacity for local communities, organisations, and government agencies. With better capacities in terms of skills, resources or processes, these entities were able to sustain themselves for longer periods of time. Hence, unpredictability in demand surges, as well as short lead times within the DMSN, were minimised.

RS, IS and IA influenced visibility. RS enabled visibility particularly when private companies were able to share critical resources such as portable telecommunication devices and damage assessment equipment such as helicopters to be able to quickly gather information on the disaster site. IS activities involved the formation of collaboration platforms for information flow to share timely updates and align priorities for the DMSN. Visibility within the DMSN minimised unpredictability in situational status on the ground and enabled appropriate interventions to be sent where needed the most. 
In general, it can be seen from the analysis that flexibility is highly influenced by resource sharing characterised by multiple companies offering manpower and their own products or services ranging from food, drinks, telecommunications and logistics equipment, infrastructure expertise, and finance to medical services. Resource sharing augments a government or NGO's typical capacity to attend to the needs of disaster victims. Multiple private companies located across regions that are willing to supply their company assets create redundancy within the DMSN and address the unpredictability in terms of where the disaster might occur.

Velocity is influenced by a mix of RS, IA, and IS. Building from RS which highly influences flexibility, the ability to find alternative suppliers from the multiple private companies offering their services positively influences velocity as well since sources for supplies are identified at a faster pace. IA also impels actors to respond quickly since it leads to benefits shared among the collaborators, e.g. a supplier engaged in a prenegotiated procurement contract with the government or NGO. Thus, having the capability to deliver swiftly results in gains and profits for the actors' organisations. IS allows DMSN actors to respond faster since these activities lead to the clarity of information, and hence, clarity on the forward actions needed within DMSNs. Collectively, these activities induce responsiveness between the collaborators and address the complexity of a DMSN with short lead-time requirements. Faster response means time saved and eventually, lives saved from further danger.

\subsection{Evaluation of DMSNRES against Future Scenario}

The future scenario identified from MMEIRS was deemed by experts as a worst-case scenario for the Philippines (Section 4.3.3). To recall, three key scenarios were emphasised in MMEIRS, should the rupture of the WVF actualise:

1. Possible splitting of the Metropolitan Manila (MM) region into four divisions: MM West, MM East, MM North and MM South (Figure 10); MM West isolated by fire;

2. $1,200,000$ people losing their residential homes and 34,000 people losing their lives;

3. $11 \%$ heavily damaged or collapsed mid-rise buildings; $2 \%$ heavily damages or collapsed high-rise buildings.

This section identifies resilience gaps against these future scenarios for further opportunities of collaboration, illustrating how resilience and cross-sector collaboration are positioned in a continuous improvement cycle.

\subsubsection{Robustness - Capacity Building}

A resilience gap means that the capacities within each of the four MM divisions (MM West, MM East, MM North and MM South) have not yet have been assessed.

A couple of collaboration opportunities exist here: (i) cross-sector collaborations during the mitigation phase targeting the improvement of the "local" capacity of each MM division, and (ii) training on first aid and evacuation procedures for households, the public and private sectors as well as NGOs contained within each division to reduce immediate dependence on response teams.

\subsubsection{Flexibility - Sourcing Redundancy}

The following resilience gaps exist in relation to flexibility - sourcing redundancy: (i) uncertainty regarding the extent of actual damage in "The Big One" adds an extra dimension of complexity to the DMSN in terms of where the critical resources can be acquired; and (ii) the national hubs of both $\mathrm{C} 1$ and $\mathrm{C} 2$ are both located in the MM (Figure 10) and each may be isolated from MM West and MM North respectively.

In terms of collaboration, the following opportunities exist: (i) the identification of multiple potential suppliers of critical resources to serve each division, (ii) collaboration with the private sector to identify private sector assets which can be found within each division, and (iii) the pre-positioning of resources within each division.

\subsubsection{Visibility - Information Reliability}

The following resilience gaps fall under visibility - information reliability: (i) in the context of "The Big One", reports from ground zero will be received in separate emergency operations centres of C3, C2 and NDRRMC, and (ii) deterministic maps instead of probabilistic maps are still being used in disaster prevention and development planning.

A couple of collaboration opportunities exist here: (i) the development of alignment mechanisms to triangulate and validate each other's information from the ground and quickly agree on forward interventions as needed on the disaster site, as well as (ii) collaboration with the University of the Philippines Nationwide Operational Assessment of Hazards (UP-NOAH) (Cadiz, 2018) on the installation of sensors and usage of probabilistic maps, enabling the analysis of real-time data to provide prompt warnings and emphasise the urgency of evacuating communities at the earliest possible time (LLCAD, 2017). 


\subsubsection{Velocity - Responsiveness}

In the velocity - responsiveness category, a resilience gap exists in terms of the challenge to move resources due to massive damage to infrastructure.

The following collaboration opportunities exist that may be of relevance to the scenario: (i) collaborating with organisations with assets for airlifting materials, and (ii) the mapping of first responders from the nearby provinces of Cavite, Laguna, Bulacan and Rizal (Figure 10).

\section{Discussion}

In this section, the results of the Philippines case study are discussed. The contributions to knowledge, implications for practice, limitations and future work are also examined.

\subsection{The Case Study of the Philippines}

In the case study of the Philippines, $\mathbf{4 6}$ collaboration activities were identified. Within each disaster management phase, various collaboration types were present. Eleven collaboration activities were identified in the disaster mitigation phase composed of joint knowledge creation (JKC) and decision synchronisation (DS). It was found that cross-sector collaboration activities within this phase typically consist of knowledge exchanges between the private, public and NGO sectors. Business continuity workshops are not only applicable to commercial supply networks but can also be adapted for public service continuity and DMSNs.

Ten out of the 46 collaboration activities were identified in the disaster preparation phase. In this phase, activities for response readiness take place. This is supported by the results which show that 6 out of the 10 collaboration activities within the preparation phase influenced responsiveness. The results also demonstrate that cross-sector collaboration in this phase involves incentive alignment (IA) and information sharing (IS). IA activities such as pre-negotiated procurement contracts enable push-button activation of production lines for relief items, ultimately enabling quick response if a disaster occurs.

A large number of collaboration activities found in the response phase echoed findings from the literature, namely that the private sector is most involved during this phase (Balcik et al., 2010; Wang et al., 2016). However, as discussed above, most literature portrays limited private sector roles, i.e. as procurement partners and providers of short-term support (Nurmala et al., 2017). The results of this research show that private sector involvement within the disaster response phase exceeds mere logistics support since, in the DMSN in the Philippines, there is the commitment of many industries to lend company-owned assets. These assets include telecommunications equipment, energy generating assets such as generator sets from electric companies, medical assistance, and assets for infrastructure-building. For a developing country like the Philippines, the privatisation of critical resources and utilities is common. Hence, the involvement of the private sector in disaster response is significant to augment government capacity.

An effective coordinating body is significant in driving resource sharing (RS) efforts. The results depict that PDRF was able to establish a network for RS which allowed businesses from different industries to pool their core resources and share risks by reducing their respective operational costs. This builds on the findings from Izumi and Shaw (2014) on the necessity to establish a coordinating body in order to have a platform of multistakeholders for discussions, information dissemination and learning.

The identification of cross-sector collaboration activities within the DMSN and throughout the four disaster management phases adds new insight to the common perception embraced by many literature proponents that the involvement of the private sector is only limited to ad-hoc contributions such as financial, product or logistics support (Nurmala et al., 2017) during disaster response. While most collaboration activities were identified within the disaster response phase in this case study, cross-sector activities embedded in the mitigation and preparedness phases illustrate that the private sector has been proactively involved in the DMOs. Collaboration activities influencing robustness were found to be JKC and DS. Robustness was built during the mitigation phase. This finding is aligned with the literature on robustness as a proactive resilience building construct (Välikangas, 2010; Durach et al., 2015). Knowledge exchanges, the co-development of standard disaster preparedness and response processes, as well as the strengthening of contingency plans to reduce vulnerability in the supply chain of critical resources are examples of activities that help build capacity and eventually lead to supply network robustness.

Collaboration activities which increase visibility are usually found in the response phase. It is acknowledged in the literature that sporadic information flow is one of the most common complexities in DMSNs (Olaogbebikan and Oloruntoba, 2017), which hinders effective relief operations. The importance of information sharing enabled by the formation of coordinating councils on the ground and at a higher level of management is emphasised to increase visibility within DMSNs. Beyond information sharing activities, resource sharing of communication equipment is found to be of critical importance (Figure 14). This study finds that the availability of telecommunications mechanisms is a critical precursor to effective information sharing. 
Building flexibility through resource sharing is commendable within the DMSN in the Philippines given the high involvement of companies in this collaboration activity. Moreover, findings illustrate that resource sharing is not limited to short-term support since private companies which willingly lend their assets or services to the public sector stem from a wide range of industries such as infrastructure, retail, and information technology. Through cross-sector collaboration, multiple sources of funds enable the pooling of financial donations which allow the public sector to adapt the interventions they provide according to the needs of the beneficiaries, thereby enabling flexibility.

Velocity is highly present in the disaster response phase. This finding reiterates the need for agile strategy within the immediate response phase as manifested by Oloruntoba and Gray (2006), Scholten et al. (2010) and Cozzolino et al. (2012). Velocity is highly influenced by three collaboration activities - incentive alignment, information sharing and resource sharing - that influence responsiveness.

The evaluation of DMSNRES against a future scenario reveals resilience gaps which can be used to identify more cross-sector collaboration opportunities and reiterates the findings from Tukamuhabwa et al (2015) that resilience building is not a linear process, but rather a continuous one.

In the literature, a DMSN is characterised by complexities identified in Table 2. Unpredictability is identified as the top issue for DMSNs. Short lead times, high stakes involved, and sporadic information flow also continue to hinder disaster management actors in effectively managing DMOs. This study finds that cross-sector collaboration builds resilience through the constructs of robustness, flexibility, velocity and visibility, and addresses complexities identified within DMSNs. Robustness in skills, resources or processes enables communities, organisations, and government agencies to sustain damage for longer periods of time, which results in reduced unpredictability in demand surges in a DMSN. Visibility within the DMSN minimises unpredictability in situational status on the ground and enables the right resources to be delivered to the right beneficiaries at the right time. Multiple private companies located in multiple locations provide their assets and create flexibility within the DMSN, thereby addressing unpredictability in terms of the location of disaster occurrence. Velocity in disaster response addresses the urgency of the delivery of resources, eventually leading to time saved and lives saved from further danger.

\subsection{Contributions to Academic Knowledge}

With the aim of answering the main research question "How can resilience be built within DMSN through cross-sector collaborations?", this article provides the following specific contributions to academic knowledge:

1. The research contributes to addressing the following research gaps:

a. Scarce literature focusing on collaboration as an antecedent of resilience;

b. SNRES in disaster management;

c. The involvement of the private sector in DMSNs limited to short-term support.

2. An innovative DMSN COLRES Analysis Framework (Figure 7) can be used to explore and contextualise collaboration and resilience considerations within DMSNs (RO1). It can be utilised as a preliminary guide for creating contextualised collaboration-resilience relationship models for organisations.

3. A new DMSN COLRES Relationship Model (Figure 11) presents a novel method for analysing crosssector collaboration activities from a resilience perspective (RO1). The model can be used by organisations within the humanitarian or private sector to identify existing collaboration activities and understand their influence in building or improving resilience.

4. Through applying the COLRES model to an empirical case study of DMSN in the Philippines, where 46 cross-sector collaboration activities were identified across four disaster management phases and linked to the resilience criteria (RO2), it can be seen that private sector involvement is not only limited to short-term ad-hoc interventions. Causal analysis between cross-sector collaboration activities and DMSNRES criteria was achieved by analysing specific outcomes of existing collaboration activities (R03). These insights can also be used by the relevant organisations.

5. As a whole, this research adds to the limited number of academic articles providing insight and tools relevant to humanitarian practitioners, as highlighted by Besiou and Van Wassenhove (2020).

\subsection{Implications for Research, Practice and Society}

\subsubsection{Implications for research}

This research provides new insights into how the private sector is involved in DMOs through collaboration with the government and NGOs. It augments existing literature on private sector involvement in DMOs, where the common perception that the sector is only involved in short-term response and recovery activities abounds. This study finds that the private sector can be operationally involved not just in post-disaster activities, but also in mitigation and preparation phases as well. This then sets a new baseline for further research on private sector involvement in DMOs. This study provides a novel COLRES framework (Figure 7) to analyse collaboration activities and their impact on DMSN resilience, but future work could apply the framework to further cases, 
such as other countries' DMSNs, or to more specific contexts such as inter-organisational collaboration. A more detailed assessment method for a potential future disaster would be relevant to the COLRES model in providing practical insights into how resilience could be built in DMSNs.

\subsubsection{Implications for practice}

The DMSN COLRES Relationship Model (Figure 11) for analysing existing processes in preparation for specific disasters can be implemented by practitioners who may be able to use this model with the goal of identifying resilience gaps and continuously improving their processes. The model provides practitioners with a way of improving processes through collaboration in order to complement government and NGO efforts with expertise from the private sector. This research also provides new insight into how the private sector can be more involved with the community to provide more sustainable and long-term contributions to society.

\subsubsection{Implications for society}

With disasters becoming more complex and frequent, and with humanitarian actors focusing more on improving their expertise, the need for all sectors of the society to collaborate and contribute to DRR is being continuously intensified. This research shows that each sector of the society can take part in DMOs to reduce unpredictability and save lives affected while increasing the speed of response and recovery. Contributions from each sector of the society can be of great assistance, not only during post-disaster response and recovery but also during predisaster mitigation and preparedness phases. As such, this research echoes the call for everyone to be involved in DRR and mitigation as a way of life.

\subsection{Limitations and further work}

As with any other research, this study is bound by limitations. The theoretical model has been applied to a case study of DMSN in the Philippines. While the three organisations interviewed were representative of different key sectors involved in DMSNs in the Philippines, the findings may not exhaustively reflect all existing collaboration activities. Relating the collaboration activities to their outcomes and eventually to the resilience criteria - although done by experts within the organisations - may still involve misjudgements due to subjective understanding of the concepts within this study.

This also calls for further research to apply the COLRES framework to different settings of disaster management globally, in addition to future work identified in section 6.3.1.

Areas of future work may include the application of the COLRES framework to pandemics, e.g. the currently ongoing COVID-19 pandemic, which did not form part of the national disaster management plans in Philippines and many other countries worldwide when this study was conducted. However, this is a rapidly growing area of massive global action and research. There are emerging examples of huge supply chain disruptions or failures in many sectors from food to medical supplies. A critical example is the shortage of medical ventilator equipment in hospitals' intensive care units. Many governments are forming unusual collaborations with existing specialised suppliers as well as manufacturers of other products to reconfigure, adapt and ramp-up the production and supply of medical ventilators (Malik et al 2020) in order to introduce resilience into the system. Although several global communities are trying to tackle shortages in many different ways with social distancing measures in place, there are proposals to use collaborative robots to reconfigure existing factories to ramp-up national production targets of ventilators (Malik et al. 2020). This is a major eye-opener in support of COLRES based approaches, particularly in cases of rare big disaster events. Much research is expected to follow in this domain in the near future.

\section{Conclusion}

Cross-sector collaboration between the humanitarian, public and private sectors builds resilience in DMSNs through capacity building, sourcing redundancy, information reliability, and logistics responsiveness. Crosssectoral knowledge exchanges, the co-development of standards and contingency plans can help build capacity. The development of a shared platform to pool and distribute resources from various clusters and industries within the private sector not only creates flexibility in DMSNs but can also potentially reduce operational costs of companies as compared to carrying out separate activities related to corporate social responsibility. Information reliability can be achieved through the development of cross-sectoral coordinating bodies, investment in technological tools leading to improved forecasts, as well as ensuring the availability of emergency telecommunications equipment by establishing partnerships with private telecommunication companies. Finally, logistics responsiveness can be achieved through partnerships with resource providers in multiple locations as well as through timely information sharing.

This study identified potential areas where the private sector, the government, and humanitarian agencies can establish stronger links. It shows that the private sector is able to go beyond existing short-term partnerships by participating in collaboration activities within each disaster management phase in order to build resilience in DMSNs. Most of the private sector's involvement in DMSNs, albeit becoming more common, has not yet been 
institutionalised in any national response plans in the Philippines. There is potential for the government to leverage on the strengths of the private sector without losing core competence and authority to drive disaster management in the Philippines. This may be more widely applicable on a global scale.

Appendix A: Guide topics for semi-structured interviews

Table 8: Guide topics for semi-structured interviews

\begin{tabular}{|c|c|}
\hline General organisation overview: & Learnings from Typhoon Yolanda \\
\hline $\begin{array}{l}\text { 1. Mandate of the organisation } \\
\text { 2. Mission and vision of the organisation } \\
\text { 3. Stakeholders / current network } \\
\text { 4. Internal organisation and responsibilities } \\
\text { of sub-units }\end{array}$ & $\begin{array}{l}\text { 1. How did the agency respond to Typhoon } \\
\text { Yolanda? } \\
\text { 2. What changed since } 2013 \text { Typhoon } \\
\text { Yolanda? } \\
\text { 3. Were there new practices in place? }\end{array}$ \\
\hline Disaster management process: & $\begin{array}{l}\text { Identification of cross-sector collaboration } \\
\text { activities within each disaster management } \\
\text { phase: }\end{array}$ \\
\hline $\begin{array}{l}\text { 1. Current process of disaster response and } \\
\text { how the team prepares for it } \\
\text { 2. How the strategies for disaster response } \\
\text { influence other disaster management } \\
\text { phases (preparation, mitigation, } \\
\text { recovery) } \\
\text { 3. Process for pre-positioning of relief items } \\
\text { 4. Presence of regional facilities } \\
\text { 5. Top products identified during rapid } \\
\text { needs assessment } \\
\text { 6. The structure of the information flow } \\
\text { from ground-up } \\
\text { 7. Sourcing strategies with procurement, } \\
\text { donations } \\
\text { 8. Criteria for accepted donations } \\
\text { 9. KPIs measured, basis of KPI targets }\end{array}$ & $\begin{array}{ll}\text { 1. } & \text { Mitigation } \\
\text { 2. } & \text { Preparation } \\
\text { 3. } & \text { Response } \\
\text { 4. } & \text { Recovery }\end{array}$ \\
\hline
\end{tabular}

\section{Acknowledgements}

The first phase of this research was funded by the Engineering and Physical Sciences Research Council (EPSRC) Global Challenges Research Fund (GCRF) through the University of Cambridge Institutional Grant 2016-17 entitled 'Resilient supply chains for disaster relief operations in South Asia'. The authors are most grateful to the case study organisations - the Department of Social Welfare and Development of the Republic of the Philippines, the Philippines Red Cross, and the Philippines Disaster Resilience Foundation for their active engagement throughout this research, as well as to reviewers and colleagues for their constructive and helpful comments. The authors would also like to thank Nicola C. Cavaleri (Centre for Languages and Inter Communication, Department of Engineering, University of Cambridge) for language editing and proofreading this article. 


\section{References}

Altay, N. and Green, W. G. (2006) 'OR/MS research in disaster operations management', European Journal of Operational Research, 175(1), pp. 475-493. doi: 10.1016/j.ejor.2005.05.016.

Altay, N. and Pal, R. (2014) Information Diffusion among Agents: Implications for Humanitarian Operations. Production and Operations Management, 23 (6): 1015-1027. doi:10.1111/poms.12102.

Ali, A., Mahfouz, A. and Arisha, A. (2017) Analysing supply chain resilience: integrating the constructs in a concept mapping framework via a systematic literature review. Supply Chain Management: An International Journal, 22 (1): 16-39. doi:10.1108/SCM-06-2016-0197.

Apta, A. (2009) Humanitarian Logistics: A New Field of Research and Action. Foundations and Trends@ in Technology, Information and Operations Management, 3 (1): 1-100. doi:10.1561/0200000014.

Baharmand, H., Comes, T., \& Lauras, M. (2017). Defining and measuring the network flexibility of humanitarian supply chains: insights from the 2015 Nepal earthquake. Annals of Operations Research, 1-40. DOI: $10.1007 / \mathrm{s} 10479-017-2713-y$.

Balcik, B., Beamon, B.M., Krejci, C.C., et al. (2010) Coordination in humanitarian relief chains: Practices, challenges and opportunities. International Journal of Production Economics, 126 (1): 22-34. doi:10.1016/j.ijpe.2009.09.008.

Balcik, B., Beamon, B.M. and Smilowitz, K. (2008) Last Mile Distribution in Humanitarian Relief. Journal of Intelligent Transportation Systems, 12 (2): 51-63. doi:10.1080/15472450802023329.

Banomyong, R. and Julagasigorn, P. (2017) The potential role of philanthropy in humanitarian supply chains delivery: the case of Thailand. Journal of Humanitarian Logistics and Supply Chain Management, 7 (3): 284-303. doi:10.1108/JHLSCM-05-2017-0017.

Beltrán Guzmán, I., Gil Cuesta, J., Trelles, M., et al. (2019) Delays in arrival and treatment in emergency departments: Women, children and non-trauma consultations the most at risk in humanitarian settings Ho, A.F.W. (ed.). PLOS ONE, 14 (3): e0213362. doi:10.1371/journal.pone.0213362.

Besiou, M. and Van Wassenhove, L.N. (2020) Humanitarian Operations: A World of Opportunity for Relevant and Impactful Research. Manufacturing \& Service Operations Management, 22 (1): 135-145. doi:10.1287/msom.2019.0799.

Blackhurst, J., Dunn, K.S. and Craighead, C.W. (2011) An Empirically Derived Framework of Global Supply Resiliency: Framework of Global Supply Resiliency. Journal of Business Logistics, 32 (4): 374-391. doi:10.1111/j.0000-0000.2011.01032.x.

Bui, T., Cho, S. and Sankaran, S. (2000) A Framework for Designing a Global Information Network for Multinational Humanitarian Assistance/Disaster Relief. Information Systems Frontiers, 1 (4): 427-442. https://doi.org/10.1023/A:1010074210709.

Cadiz, N.R. (2018) UP NOAH in Building Resilient Philippines; Multi-hazard and Risk Mapping for the Future. Procedia Engineering, 212: 1018-1025. doi:10.1016/j.proeng.2018.01.131.

Cao, M. and Zhang, Q. (2011) Supply chain collaboration: Impact on collaborative advantage and firm performance. Journal of Operations Management, 29 (3): 163-180. doi:10.1016/j.jom.2010.12.008.

Chen, J., Chen, T.H.Y., Vertinsky, I., et al. (2013) Public-Private Partnerships for the Development of Disaster Resilient Communities: Public-Private Partnerships for Resilient Communities. Journal of Contingencies and Crisis Management, 21 (3): 130-143. doi:10.1111/1468-5973.12021. 
Chowdhury, M.M.H. and Quaddus, M. (2016) Supply chain readiness, response and recovery for resilience. Supply Chain Management: An International Journal, 21 (6): 709-731. doi:10.1108/SCM-12-2015-0463.

Christopher, M. and Peck, H. (2004) Building the Resilient Supply Chain. The International Journal of Logistics Management, 15 (2): 1-14. doi:10.1108/09574090410700275.

Cooper, M.C., Lambert, D.M. and Pagh, J.D. (1997) Supply Chain Management: More Than a New Name for Logistics. The International Journal of Logistics Management, 8 (1): 1-14. doi:10.1108/09574099710805556.

Cozzolino, A. (2012) "Humanitarian Logistics and Supply Chain Management." In Cozzolino, A. Humanitarian Logistics. Berlin, Heidelberg: Springer Berlin Heidelberg. pp. 5-16. doi:10.1007/978-3-64230186-5_2.

Cozzolino, A., Rossi, S. and Conforti, A. (2012) Agile and lean principles in the humanitarian supply chain: The case of the United Nations World Food Programme. Journal of Humanitarian Logistics and Supply Chain Management, 2 (1): 16-33. doi:10.1108/20426741211225984.

CRED (2018) 2018 Review of Disaster Events. Centre for Research on the Epidemiology of Disasters.

CRED (2019) EM-DAT / The International Disaster Database. Available at: https://www.emdat.be/emdat_db/ (Accessed: 26 June 2019).

Croxton, K.L., García-Dastugue, S.J., Lambert, D.M., et al. (2001) The Supply Chain Management Processes. The International Journal of Logistics Management, 12 (2): 13-36. doi:10.1108/09574090110806271.

Dahan, N.M., Doh, J. and Teegen, H. (2010) Role of Nongovernmental Organizations in the BusinessGovernment - Society Interface: Special Issue Overview and Introductory Essay. Business \& Society, 49 (1): 20-34. doi:10.1177/0007650309350141.

Daly, H.E., Cobb, J.B. and Cobb, C.W. (1994) For the common good: redirecting the economy toward community, the environment, and a sustainable future. 2nd ed., updated and expanded. Boston: Beacon Press.

Day, J.M. (2014) Fostering emergent resilience: the complex adaptive supply network of disaster relief. International Journal of Production Research, 52 (7): 1970-1988. doi:10.1080/00207543.2013.787496.

Dubey, R., Ali, S.S., Aital, P., et al. (2014) Mechanics of humanitarian supply chain agility and resilience and its empirical validation. International Journal of Services and Operations Management, 17 (4): 367. doi:10.1504/IJSOM.2014.059999.

Dubey, R., Gunasekaran, A., Childe, S.J., et al. (2019) Empirical investigation of data analytics capability and organizational flexibility as complements to supply chain resilience. International Journal of Production Research, pp. 1-19. doi:10.1080/00207543.2019.1582820.

Durach, C.F., Wieland, A. and Machuca, J.A.D. (2015) Antecedents and dimensions of supply chain robustness: a systematic literature review Maria Jesus Saenz, P. and Xenophon Koufteros, D. (eds.). International Journal of Physical Distribution \& Logistics Management, 45 (1/2): 118-137. doi:10.1108/IJPDLM-05-2013-0133.

Eisenhardt, K.M. (1989) Building Theories from Case Study Research. The Academy of Management Review, 14 (4): 532-550.

Gabler, C.B., Richey, R.G. and Stewart, G.T. (2017) Disaster Resilience Through Public-Private Short-Term Collaboration. Journal of Business Logistics, 38 (2): 130-144. doi:10.1111/jbl.12152.

Gatti, F. (2017) Evaluating the impact of logistics consulting in the humanitarian sector. Delft University of Technology. 
Gligor, D., Gligor, N., Holcomb, M., et al. (2019) Distinguishing between the concepts of supply chain agility and resilience: A multidisciplinary literature review. The International Journal of Logistics Management, 30 (2): 467-487. doi:10.1108/IJLM-10-2017-0259.

Golgeci, I. and Ponomarov, S.Y. (2013) Does firm innovativeness enable effective responses to supply chain disruptions? An empirical study. Supply Chain Management: An International Journal, 18 (6): 604-617. doi:10.1108/SCM-10-2012-0331.

Gunasekaran, A., Subramanian, N. and Rahman, S. (2015) Supply chain resilience: role of complexities and strategies. International Journal of Production Research, 53 (22): 6809-6819. doi:10.1080/00207543.2015.1093667.

Hearnshaw, E.J.S. and Wilson, M.M.J. (2013) A complex network approach to supply chain network theory. International Journal of Operations \& Production Management, 33 (4): 442-469. doi:10.1108/01443571311307343.

Hellingrath, B., Link, D. and Widera, A. (2013) From Process Analysis to Performance Management in Humanitarian Logistics., p. 30.

HELP Logistics, KLU, IFRC (2018). Supply chain expenditure and preparedness investment opportunities. December. https://www.ifrc.org/PageFiles/91193/HELP_IFRC_ROI-Report_20190307_External.pdf

Hohenstein, N.-O., Feisel, E., Hartmann, E., et al. (2015) Research on the phenomenon of supply chain resilience: A systematic review and paths for further investigation Maria Jesus Saenz, P. and Xenophon Koufteros, D. (eds.). International Journal of Physical Distribution \& Logistics Management, 45 (1/2): 90117. doi:10.1108/IJPDLM-05-2013-0128.

Hult, G.T.M., Hurley, R.F. and Knight, G.A. (2004), "Innovativeness: its antecedents and impact on business performance", Industrial Marketing Management, Vol. 33 No. 5, pp. 429-438.

IFRC (2018) World Disasters Report 2018: Leaving No One Behind. International Federation of Red Cross and Red Crescent Societies.

ILO (2015) Needs Assessment of the Private Sector in the Philippines. International Labour Organisation.

IMF (2019) International Monetary Fund - World Economic Outlook (April 2019) - GDP per capita, current prices. Available at: https://www.imf.org/external/datamapper/NGDPDPC@WEO (Accessed: 25 April 2019).

ISM (2005) Impact of the Indian Ocean Tsunamis on the Supply Management Profession. Institute for Supply Management.

Ivanov, D. and Dolgui, A. (2018) Low-Certainty-Need (LCN) supply chains: a new perspective in managing disruption risks and resilience. International Journal of Production Research, pp. 1-18. doi:10.1080/00207543.2018.1521025.

Izumi, T. and Shaw, R. (2014) A New Approach of Disaster Management in Bangladesh: Private Sector Involvement: A New Approach of Disaster Management in Bangladesh. Risk, Hazards \& Crisis in Public Policy, 5 (4): 425-445. doi:10.1002/rhc3.12069.

Jain, V., Kumar, S., Soni, U., et al. (2017) Supply chain resilience: model development and empirical analysis. International Journal of Production Research, 55 (22): 6779-6800. doi:10.1080/00207543.2017.1349947.

JICA, MMDA and PHIVOLCS (2004) Metro Manila Earthquake Impact Reduction Study.

Johnson, N., Elliott, D. and Drake, P. (2013) Exploring the role of social capital in facilitating supply chain resilience. Supply Chain Management: An International Journal, 18 (3): 324-336. doi:10.1108/SCM-062012-0203. 
Jüttner, U. and Maklan, S. (2011) Supply chain resilience in the global financial crisis: an empirical study. Supply Chain Management: An International Journal, 16 (4): 246-259. doi:10.1108/13598541111139062.

Jüttner, U., Peck, H. and Christopher, M. (2003) Supply chain risk management: outlining an agenda for future research. International Journal of Logistics Research and Applications, 6 (4): 197-210. doi:10.1080/13675560310001627016.

Ketokivi, M. and Choi, T. (2014) Renaissance of case research as a scientific method. Journal of Operations Management, 32 (5): 232-240. doi:10.1016/j.jom.2014.03.004.

Koliba, C.J., Mills, R.M. and Zia, A. (2011) Accountability in Governance Networks: An Assessment of Public, Private, and Non-profit Emergency Management Practices Following Hurricane Katrina. Public Administration Review, 71 (2): 210-220. doi:10.1111/j.1540-6210.2011.02332.x.

Kovács, G. and Spens, K. (2009) Identifying challenges in humanitarian logistics Glenn Richey, R. (ed.). International Journal of Physical Distribution \& Logistics Management, 39 (6): 506-528. doi:10.1108/09600030910985848.

Kovács, G. and Spens, K.M. (2007) Humanitarian logistics in disaster relief operations Jahre, M. (ed.). International Journal of Physical Distribution \& Logistics Management, 37 (2): 99-114. doi:10.1108/09600030710734820.

Lee, H.L. (2004) The Triple-A Supply Chain. Harvard Business Review, p. 14.

Lewin, R., Besiou, M., Lamarche, J., Cahill, S. and Guerrero-Garcia, S. (2018) Delivering in a moving world...looking to our supply chains to meet the increasing scale, cost and complexity of humanitarian needs. Journal of Humanitarian Logistics and Supply Chain Management, 8(4): 518-532. https://doi.org/10.1108/JHLSCM-10-2017-0048.

LLCAD (2017) Scientist presses probabilistic map use for LGU plans (LCCAD). UP NOAH Center. Available at: https://center.noah.up.edu.ph/scientist-presses-probabilistic-map-use-for-lgu-plans-lccad/

Maon, F., Lindgreen, A. and Vanhamme, J. (2009) Developing supply chains in disaster relief operations through cross-sector socially oriented collaborations: a theoretical model Lindgreen, A. (ed.). Supply Chain Management: An International Journal, 14 (2): 149-164. doi:10.1108/13598540910942019.

Masood, T., McFarlane, D., Parlikad, A.K., et al. (2016) Towards the future-proofing of UK infrastructure. Infrastructure Asset Management, 3 (1): 28-41. doi:10.1680/jinam.15.00006.

Masood, T., Robinson, J. and Clarkson, P.J. (2017a) Designing a resilient supply network for the manufacture of modular buildings. In European Operations Management Association (EurOMA) Conference, Edinburgh, 1-5 July 2017, 10 pages.

Masood, T., So, E. and McFarlane, D. (2017b) Disaster Management Operations - Big Data Analytics to Resilient Supply Networks. In European Operations Management Association (EurOMA) Conference, Edinburgh, 1-5 July 2017, 10 pages.

Matin, N. (2002) Corporate Social Responsibility and Natural Disaster Reduction: Insights from Bangladesh., p. 32.

Moorman, C., Deshpande, R. and Zaltman, G. (1993) Factors Affecting Trust in Market Research Relationships. Journal of Marketing, 57 (1): 81. doi:10.2307/1252059.

Namdar, J., Li, X., Sawhney, R., et al. (2018) Supply chain resilience for single and multiple sourcing in the presence of disruption risks. International Journal of Production Research, 56 (6): 2339-2360. doi:10.1080/00207543.2017.1370149. 
NDRRMC Response Cluster (2016) The Philippine National Disaster Response Plan 2016. Philippines. https://www.preventionweb.net/files/62898_nationaldisasterresponseplanforeart.pdf

Nishat Faisal, M., Banwet, D.K. and Shankar, R. (2006) Supply chain risk mitigation: modelling the enablers. Business Process Management Journal, 12 (4): 535-552. doi:10.1108/14637150610678113.

Nurmala, N., de Leeuw, S. and Dullaert, W. (2017) Humanitarian-business partnerships in managing humanitarian logistics. Supply Chain Management: An International Journal, 22 (1): 82-94. doi:10.1108/SCM-07-2016-0262.

Nurmala, N., de Vries, J. and de Leeuw, S. (2018) Cross-sector humanitarian-business partnerships in managing humanitarian logistics: an empirical verification. International Journal of Production Research, 56 (21): 6842-6858. doi:10.1080/00207543.2018.1449977.

Olaogbebikan, J.E. and Oloruntoba, R. (2017) Similarities between disaster supply chains and commercial supply chains: a SCM process view. Annals of Operations Research. doi:10.1007/s10479-017-2690-1.

Oloruntoba, R. and Gray, R. (2006) Humanitarian aid: an agile supply chain? Supply Chain Management: An International Journal, 11 (2): 115-120. doi:10.1108/13598540610652492.

Overstreet, R.E., Hall, D., Hanna, J.B., et al. (2011) Research in humanitarian logistics. Journal of Humanitarian Logistics and Supply Chain Management, 1 (2): 114-131. doi:10.1108/20426741111158421.

PDRF (2019) PDRF / Media Newsroom. Available at: https://www.pdrf.org/media/newsroom/?set=1

Philippine Coast and Geodetic Survey (1988), 'Manila', P.G.C.S 2511, 1:250,000, Available at: http://www.geoportal.gov.ph.

PHIVOLCS (2019) Volcanoes of the Philippines.

Available at: https://www.phivolcs.dost.gov.ph/index.php/volcano-hazard/volcanoes-of-the-philippines.

Ponomarov, S.Y. and Holcomb, M.C. (2009) Understanding the concept of supply chain resilience. The International Journal of Logistics Management, 20 (1): 124-143. doi:10.1108/09574090910954873.

Prasanna, S.R. and Haavisto, I. (2018) Collaboration in humanitarian supply chains: an organisational culture framework. International Journal of Production Research, 56 (17): 5611-5625. doi:10.1080/00207543.2018.1475762.

Pujawan, I.N., Kurniati, N. and Wessiani, N.A. (2009) Supply chain management for Disaster Relief Operations: principles and case studies. International Journal of Logistics Systems and Management, 5 (6): 679. doi:10.1504/IJLSM.2009.024797.

Qiao, W. Nan, L. and Kang, T. (2010) "A study of the influence of public-private partnership on rescue efficiency in humanitarian supply chain." In 2010 IEEE International Conference on Emergency Management and Management Sciences. Beijing, China, August 2010. IEEE. pp. 114-117. doi:10.1109/ICEMMS.2010.5563489.

Rasouli, M.R. (2019) Intelligent process-aware information systems to support agility in disaster relief operations: a survey of emerging approaches. International Journal of Production Research, 57 (6): 18571872. doi:10.1080/00207543.2018.1509392.

Russell, T.E. (2004) The Humanitarian Relief Supply Chain: Analysis of the 2004 South East Asia Earthquake and Tsunami., p. 117. Available at: https://dspace.mit.edu/handle/1721.1/33352.

Sá, M.M. de, Miguel, P.L. de S., Brito, R.P. de, et al. (2019) Supply chain resilience: the whole is not the sum of the parts. International Journal of Operations \& Production Management. doi:10.1108/IJOPM-09-20170510 . 
Salem, M., Van Quaquebeke, N., Besiou, M., et al. (2019) Intergroup Leadership: How Leaders Can Enhance Performance of Humanitarian Operations. Production and Operations Management, 28 (11): 2877-2897. doi:10.1111/poms.13085.

Scholten, K. and Schilder, S. (2015) The role of collaboration in supply chain resilience. Supply Chain Management: An International Journal, 20 (4): 471-484. doi:10.1108/SCM-11-2014-0386.

Scholten, K., Scott, P.S. and Fynes, B. (2010) (Le)agility in humanitarian aid (NGO) supply chains. International Journal of Physical Distribution \& Logistics Management. doi:10.1108/09600031011079292.

Scholten, K., Sharkey Scott, P. and Fynes, B. (2014) Mitigation processes - antecedents for building supply chain resilience. Supply Chain Management: An International Journal, 19 (2): 211-228. doi:10.1108/SCM06-2013-0191.

Sheffi, Y. and Jr, J.B.R. (2005) A Supply Chain View of the Resilient Enterprise. MIT Sloan Management Review, 47 (1).

Singh, R.K., Gupta, A. and Gunasekaran, A. (2018) Analysing the interaction of factors for resilient humanitarian supply chain. International Journal of Production Research, 56 (21): 6809-6827. doi:10.1080/00207543.2018.1424373.

Smith, R. (2004), “Operational capabilities for the resilient supply chain”, Supply Chain Practice, Vol. 6 No. 2, pp. 24-35.

Soni, U. and Jain, V. (2011) "Minimizing the vulnerabilities of supply chain: A new framework for enhancing the resilience." In 2011 IEEE International Conference on Industrial Engineering and Engineering Management. Singapore, Singapore, December 2011. IEEE. pp. 933-939. doi:10.1109/IEEM.2011.6118053.

Swanson, D.R. and Smith, R.J. (2013) A Path to a Public-Private Partnership: Commercial Logistics Concepts Applied to Disaster Response. Journal of Business Logistics, 34 (4): 335-346. doi:10.1111/jbl.12031.

Tang, A. (2017) Designing Resilient Supply Chains for Disaster Relief Operations., p. 74.

The World Bank (2017) Time to Insure Developing Countries Against Natural Disasters. doi:https://www.worldbank.org/en/news/opinion/2017/10/11/time-to-insure-developing-countriesagainst-natural-disasters.

Tomasini, R.M. and Van Wassenhove, L.N. (2009a) From preparedness to partnerships: case study research on humanitarian logistics. International Transactions in Operational Research, 16 (5): 549-559. doi:10.1111/j.1475-3995.2009.00697.x.

Tomasini, R.M. and Van Wassenhove, L.N. (2009b). Humanitarian Logistics. Palgrave Macmillan, Basingstoke. Treiblmaier, H. (2018) Optimal levels of (de)centralization for resilient supply chains. The International Journal of Logistics Management, 29 (1): 435-455. doi:10.1108/IJLM-01-2017-0013.

Tukamuhabwa, B.R., Stevenson, M., Busby, J., et al. (2015) Supply chain resilience: definition, review and theoretical foundations for further study. International Journal of Production Research, 53 (18): 5592-5623. doi:10.1080/00207543.2015.1037934.

UNDRR (2015) Sendai Framework for Disaster Risk Reduction 2015 - 2030. United Nations Office for Disaster Risk Reduction. Available at:https://www.preventionweb.net/files/43291_sendaiframeworkfordrren.pdf.

Välikangas, L. (2010) The Resilient Organization: How Adaptive Cultures Thrive Even When Strategy Fails. The McGraw Hill Companies, Inc.

Van Wassenhove, L.N. (2006) Humanitarian aid logistics: supply chain management in high gear. Journal of the Operational Research Society, 57 (5): 475-489. doi:10.1057/palgrave.jors.2602125.

Waddell, S. and Brown, L.D. (1997) Fostering Intersectoral Partnering: A Guide to Promoting Cooperation Among Government, Business, and Civil Society Actors., p. 28. 
Wang, X., Wu, Y., Liang, L., et al. (2016) Service outsourcing and disaster response methods in a relief supply chain. Annals of Operations Research, 240 (2): 471-487. doi:10.1007/s10479-014-1646-y.

Wieland, A. and Wallenburg, C.M. (2013) The influence of relational competencies on supply chain resilience: a relational view, Töyli, Harri Lorentz, and Lauri Oja, J. (ed.). International Journal of Physical Distribution \& Logistics Management, 43 (4): 300-320. doi:10.1108/IJPDLM-08-2012-0243.

Wiens, M., Schätter, F., Zobel, C.W., et al. (2018) "Collaborative Emergency Supply Chains for Essential Goods and Services." In Fekete, A. and Fiedrich, F. (eds.) Urban Disaster Resilience and Security. Cham: Springer International Publishing. pp. 145-168. doi:10.1007/978-3-319-68606-6_10.

Yin, R.K. (2003) Case Study Research Design and Methods. Applied Social Research Methods. Second. Thousand Oaks, CA: SAGE Publications. 